\title{
USO DE MATERIALES EN LA CONSERVACIÓN Y RESTAURACIÓN ARQUEOLÓGICA DEL CUSICANCHA - CUSCO
}

\author{
MATERIALS USED IN THE RESTORATION OF THE CUSICANCHA - CUSCO
}

TRINIDAD AGUILAR MEZA

\begin{abstract}
* El artículo es una síntesis de la tesis de investigación desarrollada para optar el grado de Maestro en Ciencias, con mención en Conservación del Patrimonio Cultural Edificado, en la Sección de Posgrado de la Facultad de Arquitectura y Urbanismo de la Universidad Nacional de Ingeniería, Lima.
\end{abstract}

\section{RESUMEN}

El presente artículo hace referencia a los problemas que presenta la protección y conservación del patrimonio cultural del centro histórico de la ciudad del Cusco, entre los años de 1950-2005, los factores materia de estudio son la tradición y la modernidad, al estar nutridos de contenido ideológico, manipulados por las instancias del poder político, económico, social, cultural. Se trató de descubrir cuáles son los niveles de participación, influencia que se encuentra en la concepción y la práctica de la planificación, el urbanismo, la nueva arquitectura y en la disciplina de la conservación, en el esfuerzo por salvaguardar el patrimonio cultural local, sin embargo, nos encontramos con un panorama confuso y contradictorio, produciendo pérdida y destrucción en el patrimonio cultural del centro histórico del Cusco.

\section{PALABRAS CLAVE}

Conservación, centros históricos, tradición, modernidad.

\section{ABSTRACT}

This article refers to the problems presented by the protection and conservation of the cultural heritage of the historic centre of the city of Cusco, between the years of 1950-2005, subject of study factors are the tradition and modernity, to be nourished of ideological content, manipulated by the instances of power; political, economic, social, cultural. I tried to discover what are the levels of participation, influence that is found in the concept and practice of planning, urban planning, the new architecture and the discipline of conservation, in the effort to safeguard the local cultural heritage, however we find a confusing and contradictory scene, causing loss and destruction on the cultural heritage of the historic center of Cusco.

\section{KEYWORDS}

Conservation, historical centers, tradition, modernity. 


\section{Introducción}

El Cusco de los incas tenía la forma de un puma, se ordenaba a partir de un núcleo que era la plaza, un espacio abierto dedicado a la actividad pública, rodeado de casas reales, contaba con estructuras para el culto religioso y tenía servicios elementales y vías para el tránsito peatonal. La unidad básica del ordenamiento fue la kancha.

Actualmente, la manzana No 37 del Centro Histórico del Cusco, se caracteriza porque muchos edificios tienen fundamentos de muro inca sobre los cuales se levantaron las casas españolas de adobe, que fueron refaccionadas desde la Colonia para su uso contemporáneo sin perder su esencia, algunas han sido declaradas Monumento Histórico.

Uno de los conjuntos histórico-arqueológicos que forman parte de esta manzana es el Cusicancha. Se encuentra a $200 \mathrm{~m}$ al SE de la Plaza de Armas del Cusco, en el predio donde funcionaba el cuartel militar 27 de noviembre, en un área total de 6,048.10 $\mathrm{m}^{2}$. Hasta el año 2000 contaba con edificios de adobe de dos plantas, y otros de ladrillo y concreto, así como espacios libres para las actividades militares. En ese año es transferido al Instituto Nacional de Cultura, institución que emprende la intervención de conservación y restauración que ha servido como unidad de análisis para el presente estudio, en el aspecto de los materiales utilizados y las razones que lo explican.

El predio, según los estudios arqueológicos, registra una ocupación continuada desde la época preinca, existen restos de estructuras Killki (Intermedio Tardío 1000 d.C.-1400 d.C.) a nivel de cimentación, sobre las que aparecen estructuras inca (1400 d.C.1532 d.C.), coloniales y republicanas.

Respecto a los hallazgos inca, las excavaciones arqueológicas permitieron ver trazos de calles, recintos y kanchas. La intervención terminó exhibiendo un espacio de la traza urbana inca, utilizando para esto diferente material lítico.

La presente investigación se refiere al tipo de material que se ha utilizado para conservar y restaurar los muros inca de piedra y las consecuencias con rela- ción a la preservación de su autenticidad; para efectos de nuestro análisis se ha clasificado este material con las siguientes denominaciones: material histórico local, material tradicional y material moderno.

Material histórico local se refiere al material original in situ de la época prehispánica, que mediante las investigaciones arqueológicas se encontró en el predio Cusicancha. También se refiere a los líticos sueltos de los muros prehispánicos.

Material tradicional se refiere al material lítico recién canteado con las técnicas artesanales del Cusco y labrado en obra, que ha sido utilizado en las intervenciones.

Material moderno se refiere al material contemporáneo, extraño al material esencial del patrimonio arqueológico.

La tradición lítica existe y está vigente en el Cusco, los canteros, albañiles y maestros de obra despliegan su destreza en las intervenciones de conservación y restauración del patrimonio arqueológico e histórico, su uso y empleo es amplio por parte de los restauradores arquitectos y arqueólogos, con todo, la documentación es escasa.

Teniendo en cuenta lo expuesto, se formuló el siguiente problema objeto de investigación:

¿Cuáles son las razones que explican el por qué se utilizó diferente material histórico local, material tradicional y material moderno en la conservación y restauración arqueológica del Cusicancha?

Los objetivos son analizar y explicar las consecuencias del uso de material histórico local, material tradicional y material moderno en la conservación y restauración arqueológica del Cusicancha del Centro Histórico de la ciudad del Cusco.

Se ha trabajado con los siguientes supuestos básicos:

El propósito principal del tratamiento de las ruinas históricas del mundo es salvaguardar su significado histórico para presentarla al público (Feilden y Jokileto, 1993, p. 88).

La interpretación y evaluación de las ruinas depende de la calidad, localización, y dimensión de las pérdidas de materiales e integridad estructural, del conocimiento 

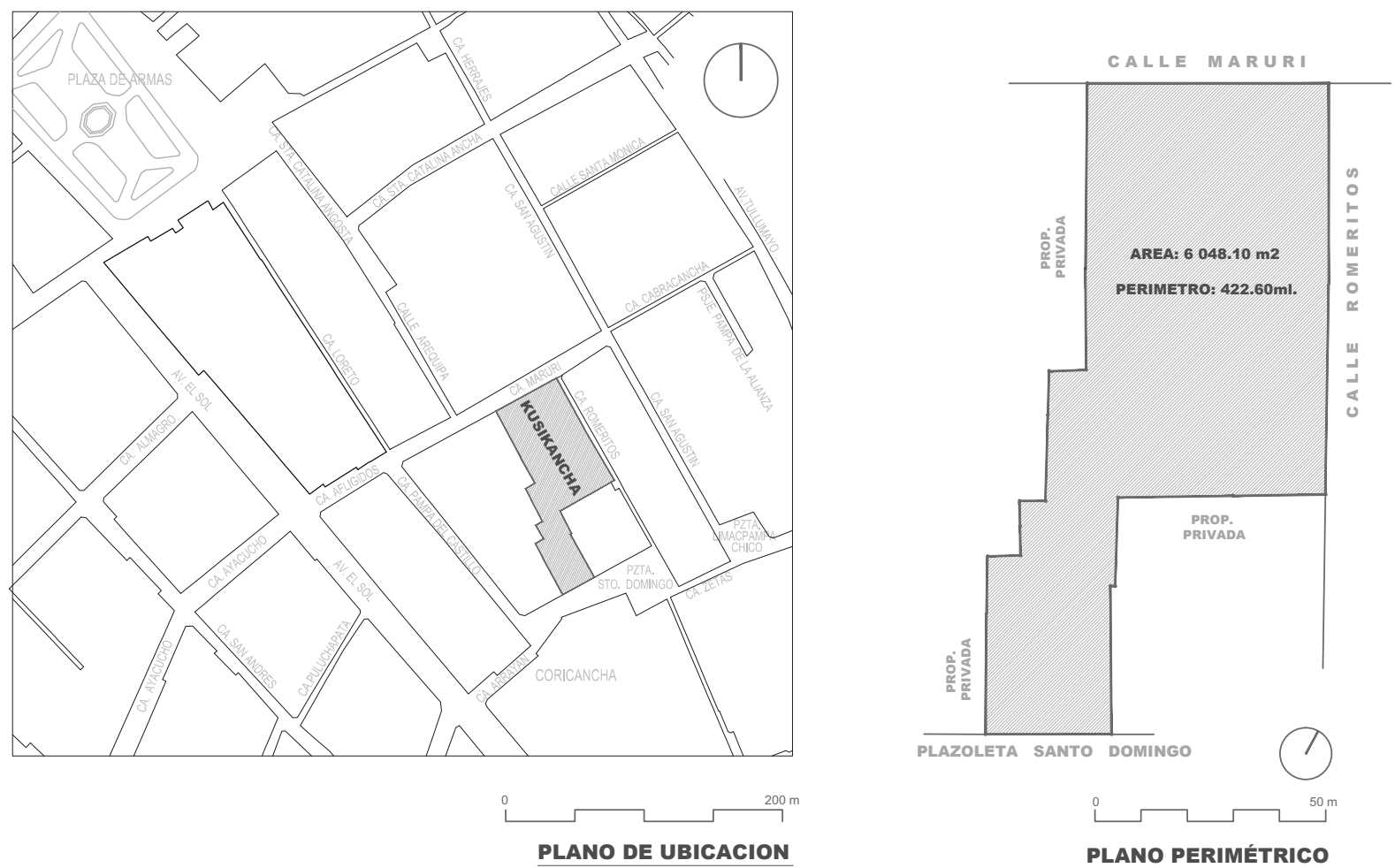

y la documentación confiables sobre las características perdidas, y de la importancia cultural de las ruinas como en la definición del monumento y su escenario" (et al.,1993, p. 88).

La significación cultural de muchos sitios no siempre está a la vista, y debe ser explicada por medio de la interpretación. Esta deberá incrementar la comprensión y el gozo, y deberá ser culturalmente apropiada" (Carta de Burra, 1999, art. 25).

Son preferibles las técnicas y materiales tradicionales para la conservación de la fábrica significativa" (et al., 1999, art. 4.2).

Los contenidos, instalaciones y objetos que contribuyen a la significación cultural de un sitio deberán permanecer en el sitio (et al., 1999, art. 10).

La hipótesis general es que a mayor uso de material histórico local y material tradicional, mayor es la preservación de la autenticidad de los materiales del Cusicancha.

Se han formulado hipótesis específicas para su verificación y estas son expuestas en el numeral 3.3 del presente artículo.
Plano 01

Ubicación del Cusicancha en el Centro Histórico del Cusco. Fuente: Ministerio de Cultura, Cusco. 


\section{Marco teórico}

La Carta de Cracovia (2000), desde una perspectiva global, define al patrimonio como: "conjunto de obras del hombre en las que la comunidad reconoce sus valores específicos y particulares y con los cuales se identifica" (el subrayado es nuestro), concordante con declaraciones internacionales como la Carta de Venecia, de 1964, y la Carta del Restauro, de 1972.

Desde la perspectiva antropológica sociocultural se entiende por patrimonio los modelos y valores que orientan las acciones y experiencias mediante las cuales hombres, mujeres y grupos de un determinado territorio, reaccionan ante sus entornos y reducen su complejidad pautando la tradición (Hernández, 2006).

El patrimonio arqueológico del Cusco, creación tangible de una cultura del pasado, es asumido intelectual y afectivamente por los cusqueños, no solo por la lectura de las crónicas de los siglos XVI y XVII, tampoco por un análisis de las estructuras físicas persistentes en la región, sino por la pervivencia de la lengua y su cultura, que implica un modo de ver el mundo y un modo de vivir con tradiciones, técnicas de uso y costumbres; el poblador cusqueño reconoce en su patrimonio material e inmaterial el sello característico del pasado, no replicado por ninguna otra cultura.

\section{Metodología}

Las técnicas e instrumentos para la recolección de datos fueron: 1).- La observación, que se sistematizó mediante fichas; 2).- Entrevistas a informantes clave y focus group, operacionalizados mediante guías de entrevista y 3).- Análisis, también sistematizado en fichas de resumen y de comentario.

El análisis de la información cualitativa comprendió descripciones detalladas sobre escenarios, contexto, historia de vida, uso de instrumentos y tecnología de trabajo en piedra.

Seguidamente se procedió a la discusión con los datos y evidencias acopiadas, realizando análisis de contenido y análisis documentario sobre la intervención, utilizando el marco teórico conceptual y el estado del arte; además, se hizo un análisis comparativo con otras experiencias ocurridas en realidades dife-

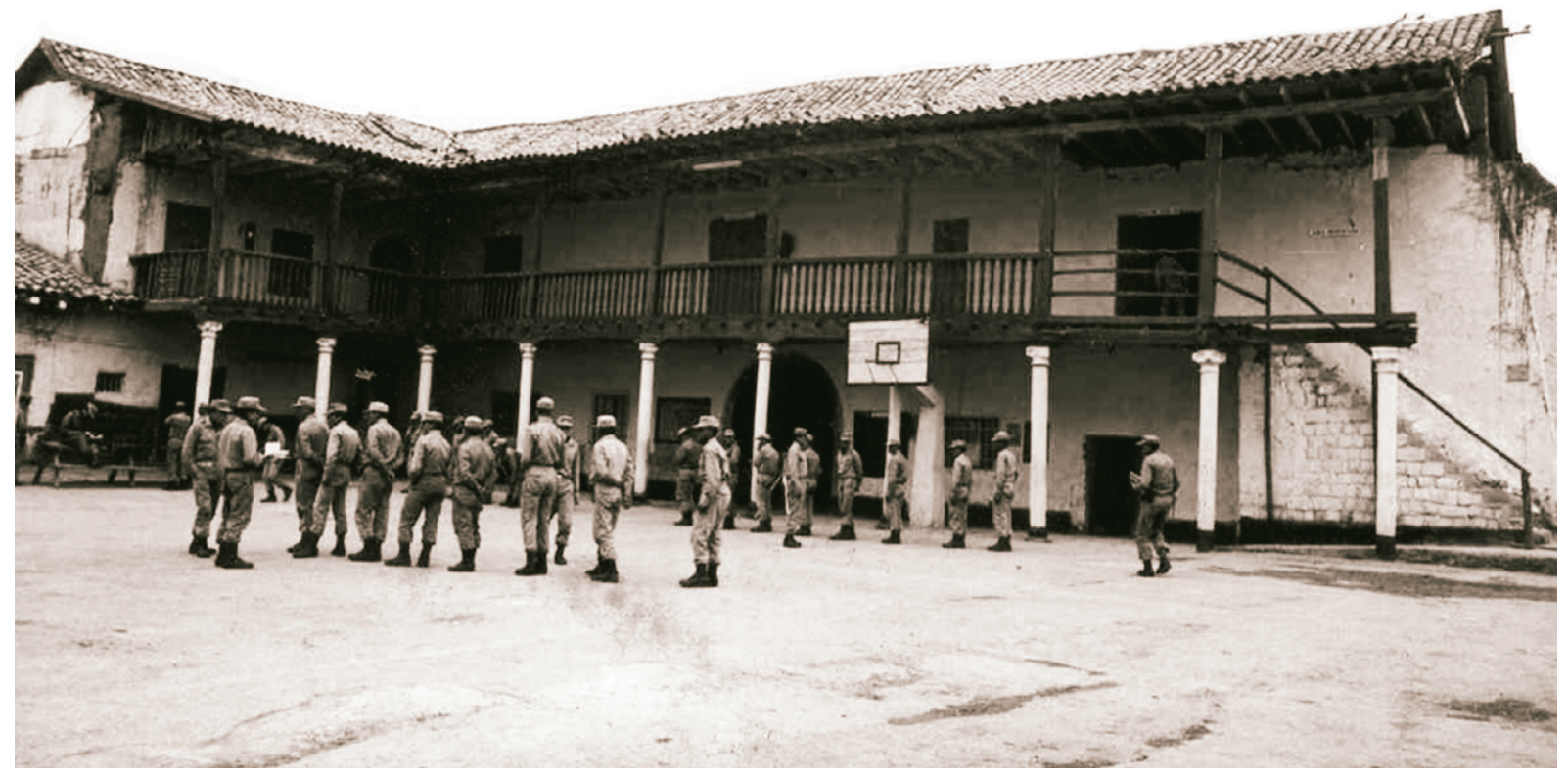


rentes al Cusicancha. Para los datos cualitativos se identificaron ideas y conceptos significativos.

\section{Resultados}

\subsection{La intervención en el Cusicancha}

La intervención del Ministerio de Cultura comprendió investigación arqueológica y puesta en valor durante los años 2001-2005 (INC, 2002, 2004a, 2004b, 2004c).

El plano de Aguilar de 1941, recuperado por Aparicio y Fernández (1986), parece ser el registro más temprano del inmueble del Cusicancha: hacia la calle Maruri, donde se ubica el sector I, muestra una edificación de dos plantas, con patio central y habitaciones alrededor, actualmente solo existen dos crujías, una sobre Maruri y otra transversal en el oeste, las crujías que ya no están posiblemente fueron destruidas o demolidas después del terremoto de 1950.

Otras estructuras contemporáneas a la época del Cuartel, en el sector II, son de tipo barraca techadas con láminas de zinc y los pisos de las áreas libres vaciadas con cemento.
De izquierda a derecha:

Figura 1

El cuartel en 1986.

Fuente: Aparicio y Fernández, 1986.

Figura 2

La casa restaurada sobre bases de muro inca.

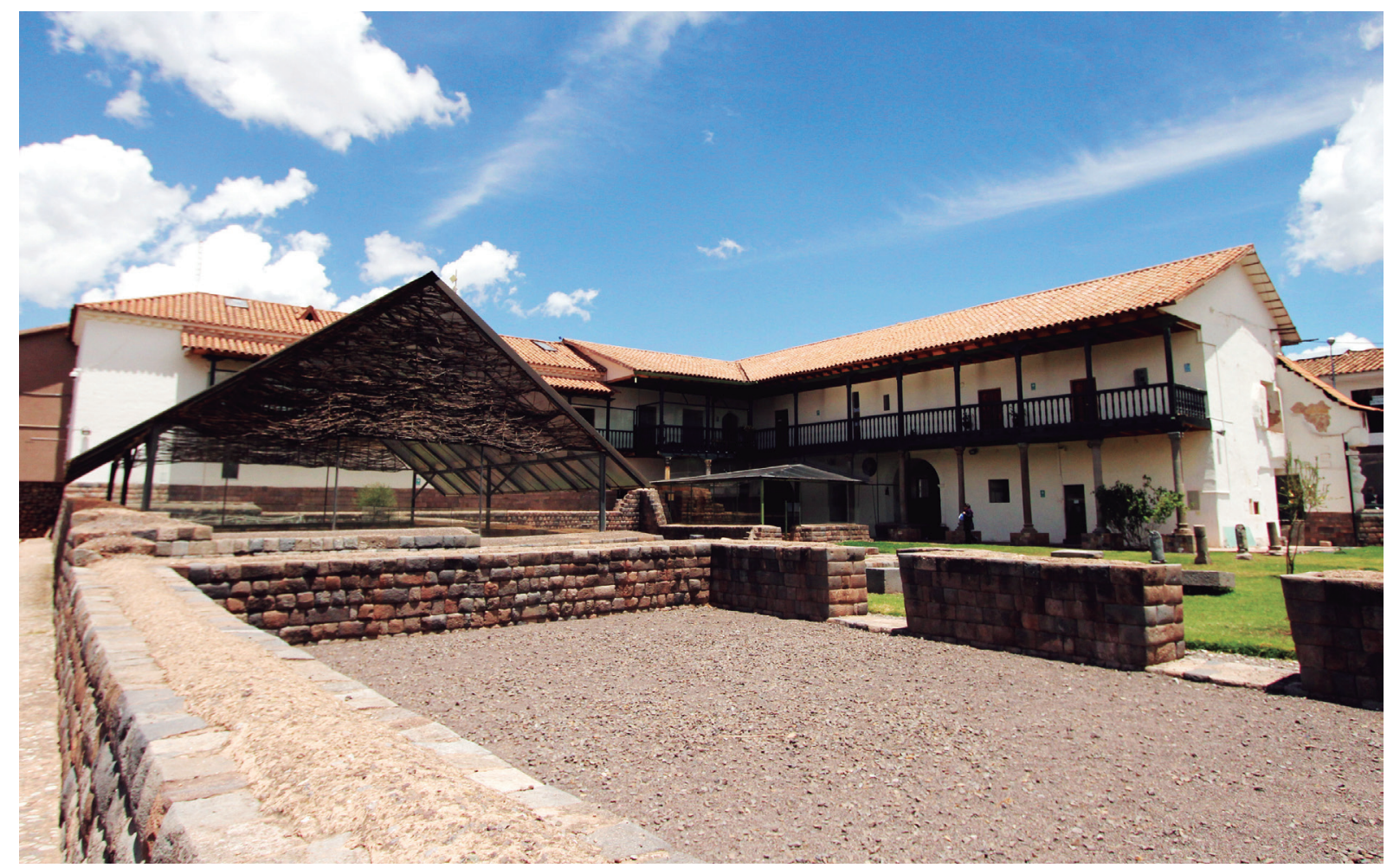



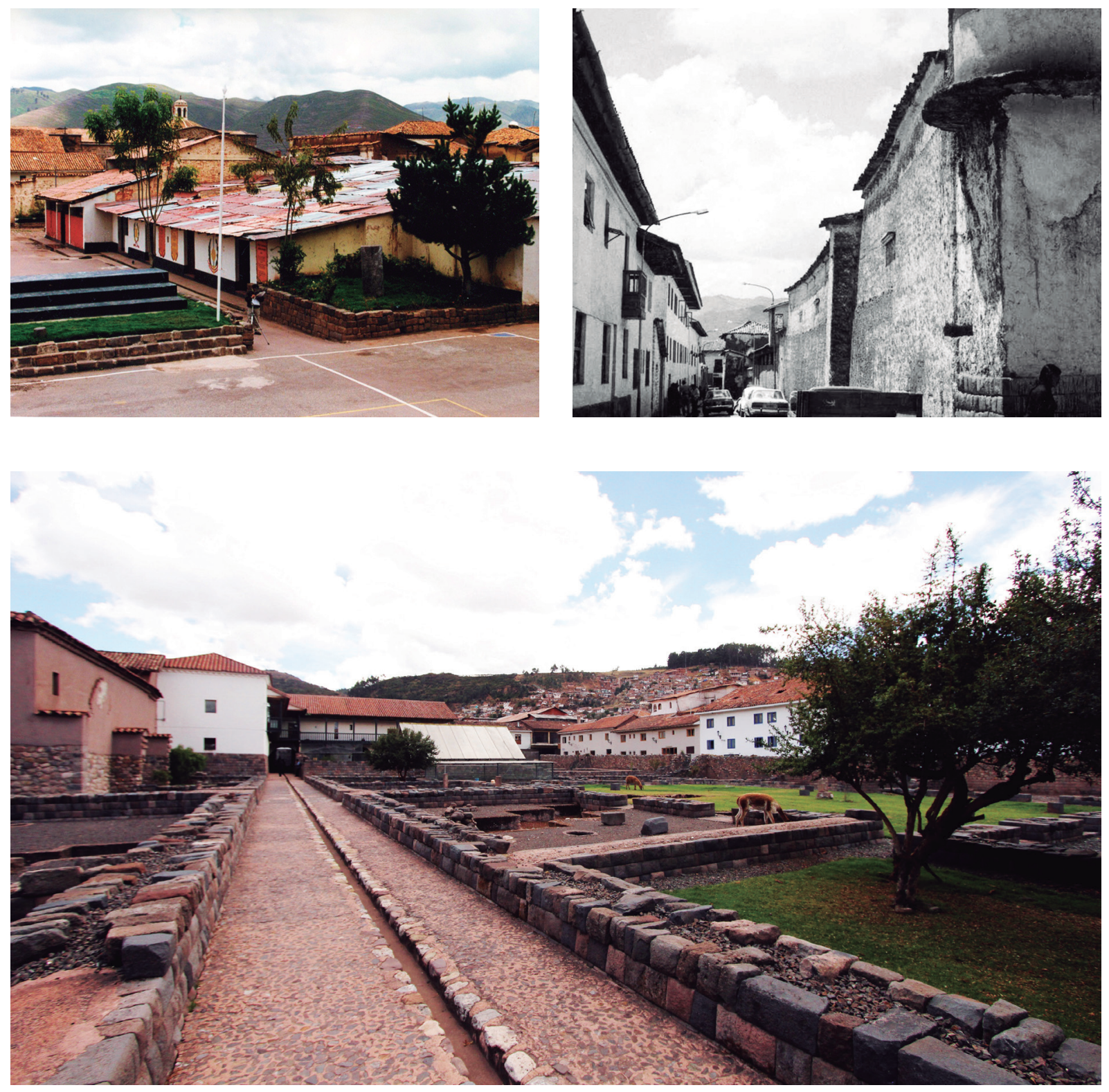

De izquierda a derecha y de arriba a abajo:

Figura 3

Calle inca recuperada dentro del predio.

Fuente: Proyecto Cusicancha.

Figura 4

Romeritos antiguo s/f .

Fuente: Proyecto Cusicancha.

Figura 5

Habitaciones y patios del cuartel s/f.

Fuente: Proyecto Cusicancha

Figura 6

Romeritos después de la intervención.

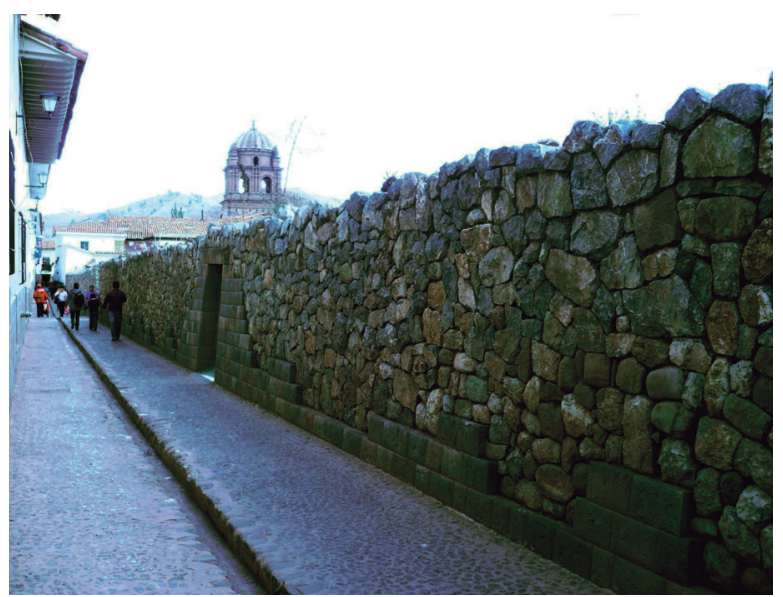


Hacia el suroeste, sector III, el Cusicancha tiene frontis a la plazoleta de Intipampa, donde en la época del Cuartel se ubicaban las cuadras del personal de tropa.

Para restablecer el tamaño de la casa hacia Maruri, se reconstruyó la crujía transversal que estaba incompleta, tomando como referencia los muros de las kanchas inca sobre las que se asentaba el edificio colonial, que subsistió a todas las modificaciones.

Por un lado, las características de los hallazgos arqueológicos prehispánicos y, por otro, las construcciones y espacios dispuestos para el cuartel, que consistían en edificaciones precarias de adobe y concreto, canchitas deportivas, caballerizas, comedores, cocinas y oficinas sin compromiso artístico ni histórico, determinaron la liberación de los pisos prehispánicos.

Esto posibilitó el descubrimiento de fragmentos de cimentación de estructuras prehispánicas, calles, componentes residenciales y kanchas, planeadas longitudinalmente hacia el Templo del Sol, Qoricancha.

Contextos inca de escombros por incendios que produjeron la precipitación de techos hacia el interior de recintos donde se ubicaban objetos cóncavos de arcilla, que podían haber servido como soportes para las vasijas alfareras en las que depositaban granos o algún otro producto, fueron cubiertos con techos de policarbonato.

En la esquina de Maruri con Romeritos, de la época del Cuartel se recuerda la existencia de una torre de control de adobe, posiblemente levantada después de que la crujía colapsó con el terremoto de 1950; además, la calle Romeritos lucía más ancha por un ensanche dispuesto en 1927 para el tránsito de vehículos motorizados que había implicado cortar el muro original inca que todavía existía, trasladándolo 1.30 $\mathrm{m}$ adentro con las mismas piedras, pero con mortero de cemento.

Después de la liberación del espacio de la calle longitudinalmente, una vez demolidos los muros de concreto contemporáneos al Cuartel, se encontró la cimentación del muro perimetral original in situ y se "restituye" o reconstruye dicho muro sobre este cimiento, con lo que Romeritos adquiere nuevamente su condición de kiqllu o calle angosta.

La reconstrucción del muro de la calle Romeritos con sillería de estilo inca de tipo sedimentario con- siste en algunas hiladas acabadas de forma dentada, y para el resguardo del predio se obtiene altura con mampostería ordinaria.

La intervención en el Cusicancha ha consistido en: 1) consolidación y recomposición de muros inca auténticos, incluyendo reintegración de segmentos, 2) restitución de tramos de la traza urbana inca sustentada en la evidencia arqueológica, que comprende la recuperación de una calle inca que corre desde Maruri hasta la plazoleta de Santo Domingo y otras calles transversales, 3) recrecimiento de muros para una reintegración parcial de las kanchas, y 4) reconstrucción o restauración recreativa en los tramos materialmente inexistentes.

El material lítico utilizado en la puesta en valor, para restituciones, reintegraciones o reconstrucción de muros y otros elementos arquitectónicos y urbanos, como puertas de doble jamba y calles, ha procedido de la recolección de unidades líticas prehispánicas sueltas que se encontraron desperdigadas por todo el conjunto del Cusicancha y también de la adquisición de material proveniente de varias canteras de la región.

Revisando los muros y elementos restaurados, se verifica que no se hizo una selección estricta del material lítico usado, se encuentran líticos sueltos prehispánicos rejuntados del conjunto que se reutilizaron y reubicaron en la reintegración de faltantes y reconstrucción de elementos, por esta razón es notoria la diversidad a través del conjunto, se puede apreciar líticos con pátina, sin pátina, de diferente coloración y acabado, indistintamente.

Las unidades líticas nuevas utilizadas en la restauración de muros, han sido marcadas con una hendidura circular pequeña, sin embargo, en muchos líticos nuevos falta esta marca.

\subsection{Referencias sobre restauración arqueológi- ca en el Cusco: antecedentes}

En 1987, Daniel Schávelzon publicó un estudio sobre la restauración arqueológica dentro del ámbito de América Latina, el artículo "Cambio y transformación: la restauración arqueológica en América Latina entre 1970 y 1980 " tiene un apartado especial sobre el Cusco, en el que señala que a partir de la década del 50, particularmente después del terremoto, surge un cuerpo teórico y experimental, que se define porque en el Perú hay una coexistencia de edificios 
arqueológicos y coloniales, y aunque menciona algunas reconstrucciones como en la Huaca del Dragón, donde se rehízo con cemento mezclado con tierra los relieves originales de barro; después de los cursos sobre restauración impartidos en el Cusco con la intervención de arquitectos y arqueólogos entrenados y las nuevas corrientes críticas de la arqueología, las técnicas se modifican, cita como ejemplo el Plan COPESCO, que si bien es cierto produjo cambios profundos en el uso de la ciudad del Cusco, en cuanto a técnicas de restauración opina que fueron las mejores.

Menciona la labor de Roberto Samanez en Pisaq, donde dirigió restauraciones a partir de una propuesta que redujo la intervención a una recomposición, consolidación y anastilosis, previo registro reticulado y estratigráfico.

Se ha constatado que estas técnicas fueron asimiladas masivamente en el Cusco, y se replican hasta la fecha.

La opinión de Schávelzon data de 1987. A la fecha la actividad restaurativa en el Cusco es cada vez más amplia, se irradia desde la ciudad a lo más recóndi-

to de la región, decenas de profesionales emprenden el registro y la restauración del patrimonio arqueológico, partiendo de una política de recuperación y conservación del patrimonio para la identidad de los pueblos y para su puesta en valor.

No se ha encontrado un estudio sistemático sobre el uso de materiales en la conservación y restauración arqueológica, aunque el Ministerio de Cultura conserva un archivo, no es completo, no se ha encontrado un análisis o registro sistemático sobre este aspecto de la práctica de la conservación y la restauración arqueológica en la región, tampoco una propuesta explícita aunque se encuentra implícita en los hechos, y este es el aspecto que se ha abordado en el presente estudio.

\section{Discusión sobre el uso de materiales en la con- servación y restauración arqueológica del Cusi- cancha}

\section{Autenticidad}

En general, la calidad de auténtico implica que el objeto es cierto y verdadero, por los caracteres, requi- sitos y circunstancias que en ello concurren, y con relación a un bien cultural, se entiende que auténtico es el original, creado por el autor, en oposición a copia, o el real y genuino en oposición a falso.

La autenticidad es un factor fundamental que determina la valoración de un bien cultural como tal, específicamente respecto al patrimonio arquitectónico, el documento "Principios para el análisis, conservación y restauración de las estructuras del Patrimonio Arquitectónico" (2003, Art. 1.2) señala que el valor y la autenticidad del patrimonio arquitectónico no pueden fundamentarse en criterios predeterminados porque el respeto que merecen todas las culturas requiere que el patrimonio material de cada una de ellas sea considerado dentro del contexto cultural al que pertenece.

El mismo criterio operaba en La Carta de Nara de 1994, este documento contiene la importancia de la diversidad cultural y de las expresiones particulares que se deben respetar, cada cultura sustenta la autenticidad, al identificar y comprender los valores de su patrimonio.

La Declaración de San Antonio (1996) anota una diferencia entre el ámbito americano y los otros continentes. En América existe, por un lado, el patrimonio autóctono y, por otro, la herencia de los colonizadores europeos; sumado a la presencia africana y también asiática, hace que seamos pluriculturales y, por lo tanto, con una identidad continental dinámica, en la que las diversas identidades con valores de unos y otros deben coexistir sin imposición de predominios jerárquicos.

El Perú, como otros países, es pluricultural desde tiempos inmemoriales, no solo desde la llegada de los europeos, si no veamos cómo la arqueología y la etnohistoria nos muestran la coexistencia de diversas nacionalidades incluso en un mismo tiempo y espacio, como en la época inca.

Por lo tanto, el valor integral de nuestro patrimonio cultural se puede entender solo a través de un estudio objetivo de la historia, de los elementos materiales inherentes al patrimonio material y una profunda comprensión de las tradiciones intangibles relacionadas con el patrimonio tangible. 
Los materiales sustanciales del patrimonio cultural, deben ser identificados, analizados y protegidos, por ser el principal componente de su autenticidad. Solo la fábrica histórica es auténtica mientras que las interpretaciones realizadas a través de las restauraciones no lo son, estas pueden solo representar auténticamente el significado de un sitio tal como es entendido en un momento dado (La Declaración de San Antonio, 1996).

La Carta de Burra, Carta del ICOMOS Australia para Sitios de Significación Cultural (1999), ofrece directrices operacionales que pueden servir de modelo para definir y proteger la autenticidad en la conservación y gestión de los sitios de significación cultural.

Es primordial comprender la significación cultural, luego desarrollar políticas y finalmente gestionar el sitio de acuerdo con esas políticas.

Acepta cautelosamente los cambios, si sirven para proteger y hacer útil a un sitio, que deben ser lo menos posible a fin de que se conserve la significación cultural.

Así, las Cartas reconocen que cada cultura asume su patrimonio como nace de su propia identidad. La identidad cultural, entendida como el conjunto de valores, orgullo, tradiciones, símbolos, creencias y modos de comportamiento que funcionan como elementos aglutinantes dentro de un grupo social y que actúan para que los individuos que lo conforman puedan fundamentar su sentimiento de pertenencia, es la que finalmente definirá la autenticidad de su patrimonio cultural.

\section{Autenticidad y diversidad cultural}

La ciudad del Cusco ostenta expresiones culturales de distintas épocas de su historia, la estructura urbana arquitectónica es de excepcional valor.

Después de los daños ocurridos con el terremoto de 1950, ha seguido sufriendo alteraciones con la pérdida de patrimonio cultural, sobre todo en el Centro Histórico a consecuencia de la intensa actividad comercial y turística.

De las 108 manzanas del Centro Histórico de Cusco, la manzana 37 cercana al Qoricancha es una manzana representativa por varias razones, dentro de esta se ubicaban el Cusicancha, el Sancacancha y parte del
Acllahuasi del tiempo de los incas, contiene un alto porcentaje de estructuras y piedras sueltas prehispánicas y también edificaciones coloniales, algunas declaradas Monumento Nacional como las siguientes: Inmueble 263 de Santo Domingo, 347 de Pampa del Castillo, 365 de Pampa del Castillo, 405 de Pampa del Castillo y 340 de la calle Maruri, que es el ex Cuartel militar 27 de Noviembre, hoy Cusicancha.

Actualmente predomina la actividad comercial y de servicios, existen tiendas, oficinas, restaurantes turísticos, chicharronerias, hoteles y áreas de residencia especial en los interiores.

Previo a la discusión materia de nuestro estudio, nos aproximaremos a las características y patrones urbano-arquitectónicos incas conocidos en esta parte de la ciudad, mediante una mirada a toda la información publicada sobre lo que se pensaba de la Manzana 37, sobre el tipo de materiales y tipos de aparejo que se distinguen en el Cusco, con lo que se podrá deducir lo que correspondería al Cusicancha.

\section{Las kanchas de la Manzana 37}

El diseño urbano inca en el Cusco contaba con un elemento fundamental conocido como kancha, consiste en un recinto rectangular cercado con el que formaban bloques a modo de manzanas, el recinto cercado integraba un patio con una sola puerta de acceso, rodeado de habitaciones individuales no conectadas entre sí, formando patios esquineros.

El Dr. Manuel Chávez Ballón, sobre la ciudad en forma de puma, opinaba que el sector de la actual Manzana 37:

\footnotetext{
"Correspondía a la parte central del felino muy cercano al vientre, además, este espacio estaría dividido por tres calles longitudinales y por otras tres calles transversales formando un diseño ortogonal de nueve subunidades donde se construyeron las canchas que probablemente tenían como patrón el de tener un vano de ingreso por el lado este que llevaba a un patio de distribución central que permitía un fácil acceso a ocho recintos distribuidos a dos por cada lado; las calles tendrían un ancho de $2.65 \mathrm{~m}$ y las canchas tuvieron como patrón las medidas de $47.5 \mathrm{~m}$ a $48 \mathrm{~m}$ de largo por $43.89 \mathrm{~m}$ de ancho, dentro de las cuales se encuentran distribuidos simétricamente ocho recintos de $12.9 \mathrm{~m}$ de largo por $10.10 \mathrm{~m}$ de ancho; siendo el ancho del muro de $0.84 \mathrm{~m}$. El patrón de cancha y re-
} 
cinto inca sugiere las mismas dimensiones en el resto de la manzana actual, incluyendo el sector en donde se tiene proyectado realizar la construcción del centro de investigación e interpretación arqueológica en un área de 689.2 m²" (Bermúdez, 1984).

Refiriéndose al predio del Cuartel 27 de Noviembre.

\section{Tipos de piedra}

Los cronistas españoles señalan que la élite gobernante inca tenía control sobre las canteras, estas se explotaban de acuerdo con la planificación estatal. Betanzos, Cobo y Pedro Cieza de León mencionan algunas canteras como Salu Oma, Huayrangallay, una en Mohina, Huaqoto, Qochahuasi y Rumiqolqa, de donde se extraen rocas análogas andesitas.
El aparejo de tipo celular se construye con elementos que se ordenan formando estructuras celulares o rosetas a partir de algunos puntos centrales que se irradian, estos son de calizas, andesitas y a veces de areniscas. La forma de las piedras varía, pueden ser poligonales, pentagonales, hexagonales, de aspecto almohadillado o simplemente desbastado, la textura de los paramentos puede ser áspera o lisa. Las esquinas y las jambas de vanos en este tipo de muros se refuerzan con aparejo sedimentario o engastado (Cabracancha con Tullumayu, y Ahuacpinta con Zetas), se usan en canalizaciones, andenerías, contención de terrazas y rellenos, cercos de canchas y muy raramente en paredes de edificaciones (canalizaciones del Saphy, Cabracancha, Santa Mónica, Santa Clara, Ataúd).

El Qoricancha y otros edificios de las inmediaciones en el centro del Cusco fueron construidos con andesita, y los afloramientos más cercanos de estas piedras están en Huaqoto y Rumiqolqa.

Las canteras de Saqsayhuaman son de calizas y dioritas, Huaqoto y Rumiqolqa de andesitas y basaltos, Yucay de calizas y Cachiqata de granitos.

\section{“EL DISEÑO URBANO INCA EN EL CUSCO CONTABA CON UN ELEMENTO FUNDAMENTAL CONOCIDO COMO KANCHA, CONSISTE EN UN RECINTO RECTANGULAR CERCADO CON EL QUE FORMABAN BLOQUES A MODO DE MANZANAS".}

Agurto (1987) bautizó como tipo engastado al ensamblado, estos aparejos son construidos con grandes piedras que se unen unas a otras a la manera de piezas de un rompecabezas, engastándose mutuamente, donde la unión produce una gran estabilidad por el número de ángulos. Las piedras usadas fueron andesitas, dioritas y basaltos.
Los canteros y picapedreros del Cusco identifican, diferencian y conocen las rocas caliza, andesita, diorita, granito, arenisca, conocen los sitios de donde provienen y cuáles son sus características, conocen también para qué aplicación sirven y en qué sitios arqueológicos se encuentran.

\section{Tipos de aparejo}

Respecto a los aparejos, Agurto (1987, pp. 144-176) planteó la clasificación: rústico, celular, engastado, sedimentario y ciclópeo, basado en el material, la forma y calidad del trabajo y el ordenamiento del aparejo.

El aparejo rústico es con piedras sin labrar, pueden ser areniscas o calizas, se forma simplemente encimando las piezas para muros de contención, sostenimiento de terrazas y andenes, así como chullpas, viviendas domésticas o chozas. Existen ejemplos en Pantipata, Tres Cruces, Atoc Saicuchi, Huaynapata, Callejón de la Conquista, Quiscapata, Sapantiana, calle Hospital, etc.
Se usan como elementos de contención de rellenos o laderas (caso de Hatun Rumiyoc) y, generalmente, como elementos de refuerzo de otros aparejos (Cabracancha y Ahuacpinta) o como parte de edificaciones de gran importancia (Templo de las Tres Ventanas de Machu Picchu), en el Cusco son buenos ejemplos los del Pasaje Inca Roca, calle Suecia y algunos sectores de los baluartes de Sacsayhuamán.

El aparejo de tipo sedimentario está formado por piedras calizas, andesitas o basaltos asentados en hiladas horizontales, con piezas líticas de formas trapezoidales, rectangulares, cuadrangulares o paralelepípedo rectangular, el perfil de las caras puede ser almohadillado, convexo, plano y biselado, de junta labrada y pulida, de estructura transversal de tipo "denticulado" o "encajado". En casos especiales, los sillares pueden tener trabas, espigas o grapas, que aseguren su unión. Verticalmente, las piedras pueden superponerse formando hiladas de igual altura o de dimensiones distintas o creando ritmos.

Se usó para construir cercos y paredes de recintos así como edificios públicos y habitacionales, en forma excepcional para canalizaciones de los ríos Huanca- 


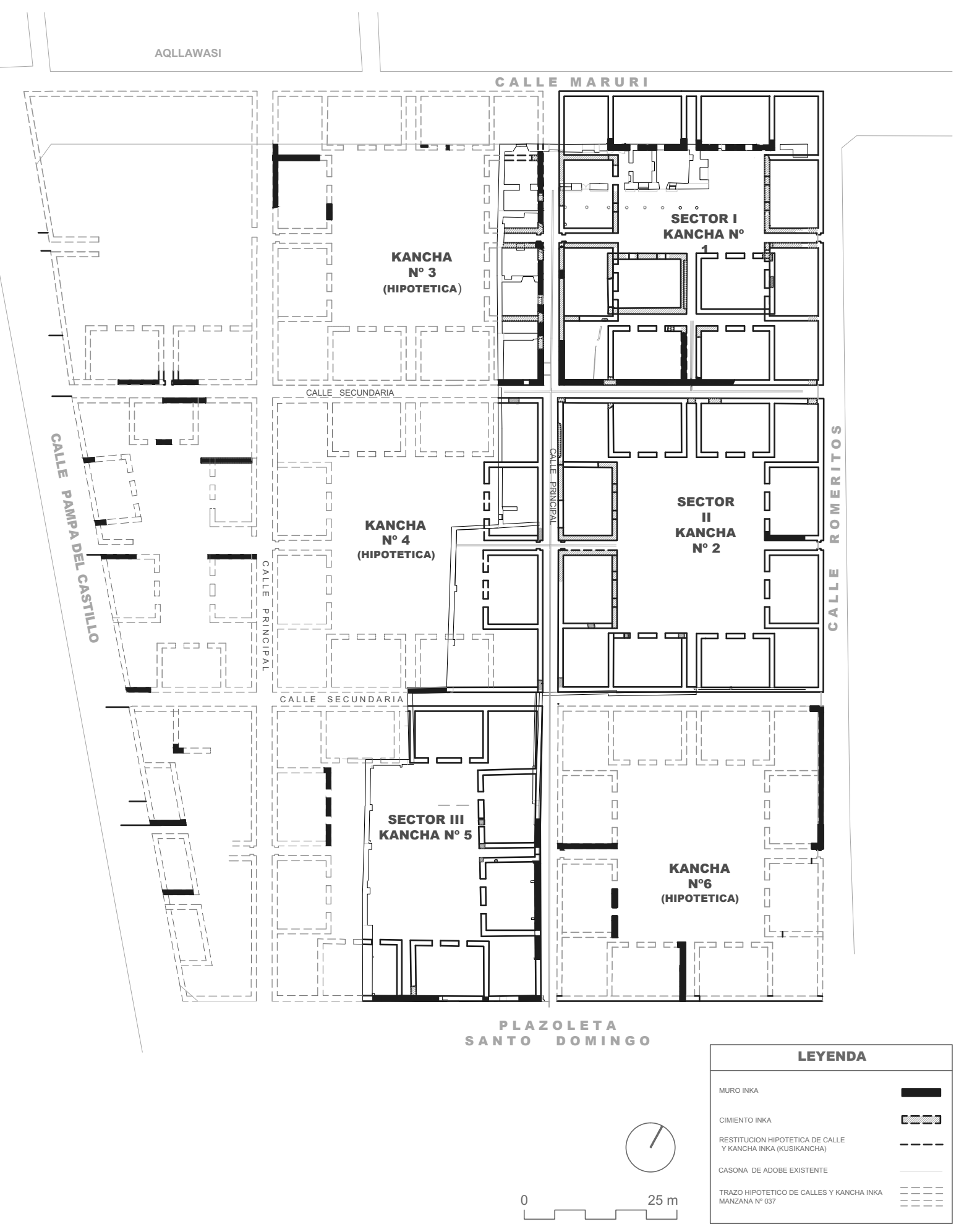




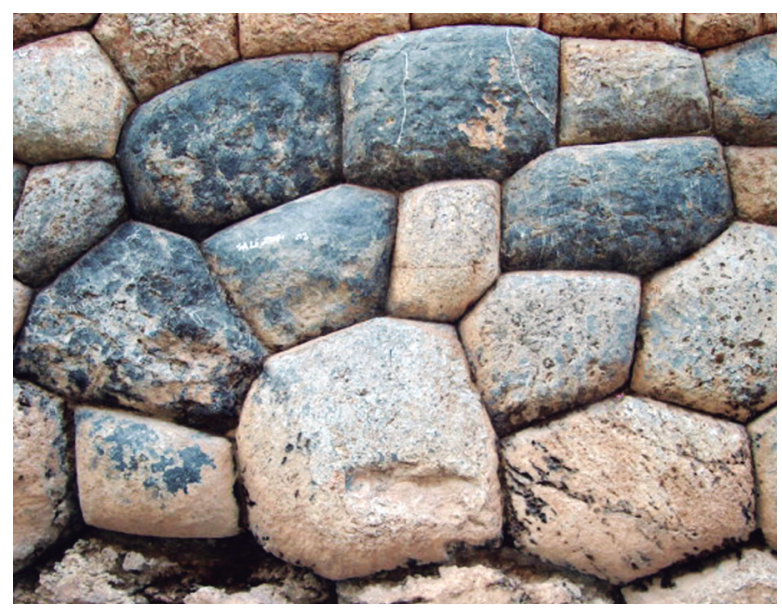

ro y Huatanay. Este tipo de paramento lo tenemos en el Qoricancha, Cusicancha, Cassana, Sacsayhuamán, Ahuacpinta, Santa Catalina Angosta, Callejones de Romeritos y del Sol, etc., el muro curvo del Qoricancha, la esquina redondeada del portal de Belén con la calle Triunfo, el muro de sillares decrecientes del Intikijllu (calle Loreto) y los recios almohadillados de la calle Maruri.

Los aparejos de los muros de grandes dimensiones son del tipo ciclópeo, generalmente de calizas y con menor frecuencia andesitas, el trabajo necesario sería desbastar los bordes para asegurar la unión entre ellas, los perfiles de las caras son naturales, relativamente ásperos y en algunos casos lisos. De este tipo son los seis bloques enormes de Ollantaytambo, los bloques yuxtapuestos de los baluartes de Sacsayhuamán, y también los hay para estabilizar laderas inestables o para constituir murallas o bastiones de fortalezas o de lugares sacros fortificados como Sacsayhuamán y Machupicchu.

Agurto establece una relación entre el tipo de piedra y el elemento arquitectónico, así, los grandes dinteles de piedra, piedras con engaste, piedras con elaboradas aristas, con entrantes y salientes, serían andesitas o dioritas; los muros de contención generalmente calizas o piedras de campo sin labrar; la canalización de los ríos con duras andesitas de ajustado aparejo sedimentario.

También existe relación entre el aspecto de los aparejos y la función a cumplir, se escogía determinado aparejo para construir tal tipo de muro, no solo por

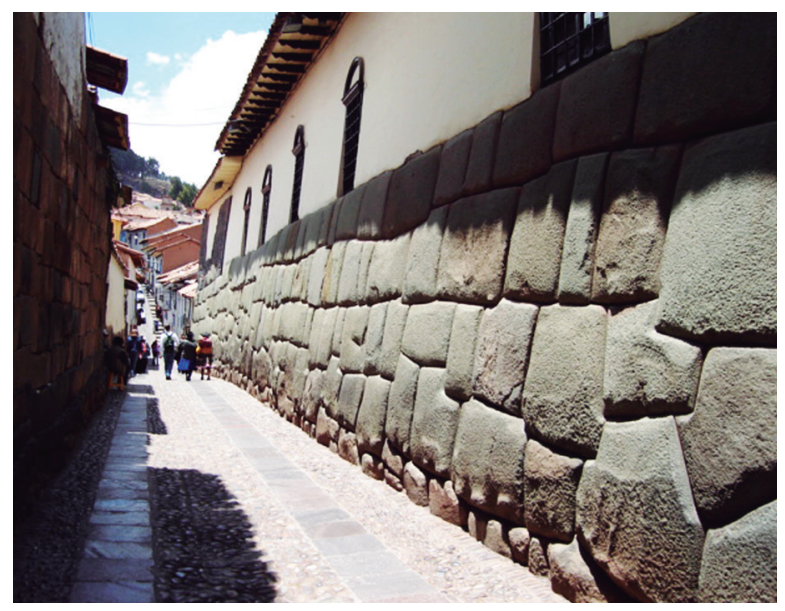

razones técnicas, sino también por razones estéticas y probablemente religiosas, así, los aparejos rústicos y celulares se encuentran en obras utilitarias, los aparejos engastados, para reforzar basamentos y esquinas o construcción de muros de edificios sacros, y los aparejos sedimentarios, para formar las cercas y paredes de los más importantes edificios públicos, en cambio los ciclópeos, para construir las defensas y bases de las acrópolis inca (Agurto, 1987:162-163).

\section{Investigación arqueológica}

El Centro Histórico de la ciudad del Cusco tiene como característica notable la superposición de restos arquitectónicos prehispánicos e hispánicos, lo que le confiere a su patrimonio edificado de una amalgama muy particular, incluyendo a la fecha edificios republicanos y contemporáneos, en un tejido urbano afianzado a través de los años por haber tenido una ocupación continuada.

Los pequeños restos arquitectónicos del Cusco pre Pachacútec, como son Killke, consistentes en fragmentos soterrados de bases de muros y de canales, están siendo documentados a través de recientes excavaciones arqueológicas, a diferencia de los restos de la arquitectura inca pos Pachacútec que se yerguen majestuosos como base de muchos edificios de origen hispano colonial.

Cuando el Instituto Nacional de Cultura, hoy Ministerio de Cultura, recibió el local del Cuartel militar 27 de Noviembre para utilizarlo como su local institucional, en cumplimiento de las normas vigentes y 
el Reglamento de Investigaciones Arqueológicas por afectación de obra pública, realizó un Proyecto de Evaluación Arqueológica PEA.

El proyecto de investigación arqueológica tuvo en cuenta que este predio se encuentra en la Manzana No 37 del Centro Histórico del Cusco, y las hipótesis sobre la existencia de material cultural de la época inca y de rastros de la traza urbana inca, fueron confirmadas después de las excavaciones arqueológicas.

La primera idea de construir un local nuevo para el Instituto Nacional de Cultura del Cusco fue perdiendo lugar en vista de los importantes hallazgos, como se colige de la revisión de la documentación correspondiente, los funcionarios del INC tuvieron algunas reuniones para discutir la forma de intervención y las alternativas de uso del espacio. Se han encontrado proyectos de un edificio en ciernes, pensado para salvar la volumetría de la casa en la esquina de Maruri con Romeritos, puesto que esta área había quedado vacía rompiendo con la esquina de la manzana que de alguna manera se guardaba con la torre de control que existía en la época del Cuartel.

Se proyectaban edificios con espacios abiertos coincidiendo con los patios centrales de las canchas inca que se perfilaron en los restos arquitectónicos soterrados hallados durante las excavaciones arqueológicas; y hacia Santo Domingo, el proyecto nuevo contemplaba edificios hasta de tres niveles.

En este punto, el Instituto Nacional de Cultura, tuvo que tomar una decisión; a la luz de los documentos y

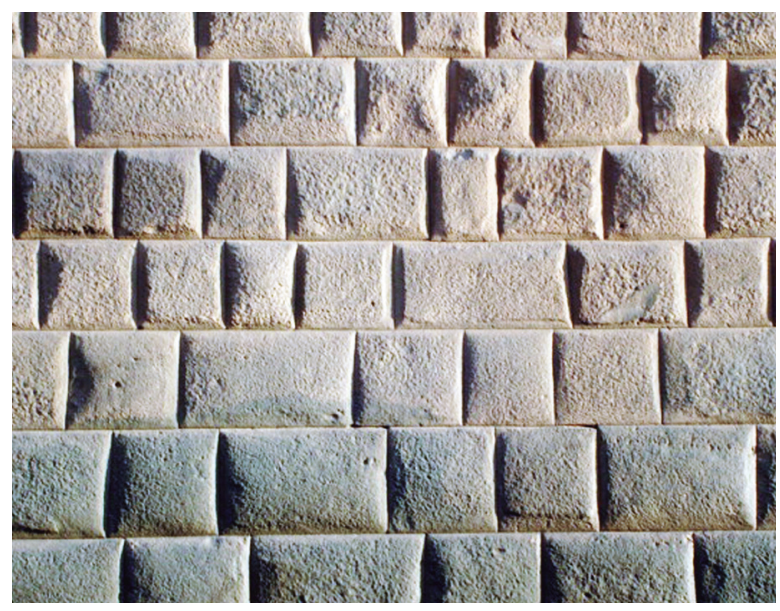

de los hechos, obviamente desechó la alternativa de la nueva construcción y decidió la liberación de los pisos inca. Se sabe que Luis Lumbreras, tuvo mucho que ver con la determinación de dejar el espacio para mostrar la evidencia inca:

\footnotetext{
"A nosotros nos costó muchísimo lograr que la casa de Pachacútec se dejara tal cual, y se preservase como monumento arquitectónico incaico. Estaba debajo de un cuartel. Se logró recuperarlo, pero costó muchísimo" (Entrevista a Luis Lumbreras, recuperada el 27 de agosto de 2010 del portal Valicha.com).
}

Carmen Farfán, arqueóloga del INC, manifiesta:

\begin{abstract}
"En el caso de la manzana 37, hubo dos posiciones encontradas respecto a qué se hacía con todo este hallazgo importante de la cancha inca, porque era una cancha directamente asociada al Qoricancha, entonces definitivamente tenía que respetarse esa parte inca, en cuanto a la parte colonial se respetó como vestigios y también como una cuestión funcional... Se impuso la parte arqueológica que era la que iba a permitir una lectura mejor del Qoricancha" (entrevista del 20 de octubre de 2010).
\end{abstract}

Se sabe que los restos arqueológicos siempre fueron motivo de curiosidad por su antigüedad, belleza y valor material, entre estos los objetos muebles ocuparon el primer lugar de interés, pero el objeto inmueble generalmente era saqueado y abandonado; en el Perú no se encuentran fácilmente ejemplos de conservación de restos arqueológicos arquitectónicos sino hasta entrado el siglo XX, Julio C. Tello lo hizo 
en Pachacamac hacia 1940, Arturo Jiménez Borja en Puruchucu, de 1953 a 1961 (Hayakawa, 2002).

En el Cusco, las primeras intervenciones de conservación y recuperación del patrimonio arqueológico se realizaron en 1934, para celebrar el IV Centenario de la fundación española de la ciudad, la Comisión Especial presidida por el Dr. Luis E. Valcárcel emprendió trabajos de reconstrucción en los restos incaicos de la ciudad como los de la calle Loreto y también se hicieron excavaciones que pusieron al descubierto nuevas estructuras en Sacsayhuamán y se excavó y limpió parte de Qenqo. Estas labores siguieron en Ollantaytambo, Tarawasi, el Intihuantana de Machu Picchu, Pikillaqta y posteriormente fueron continuadas entre 1946-1948 por el Patronato Departamental de Arqueología del Cusco (Samanez, 1986).

\subsection{Verificación de hipótesis}

Hipótesis 1. El material histórico local conservado en la intervención del Cusicancha, garantizó la preservación de la autenticidad del material del patrimonio arqueológico.

Para efectos de nuestro análisis, se ha dicho que el material histórico local es el material original in situ, componente de los muros inca y, posteriormente, cuando nuestra investigación arroja resultados, se incorpora también al material original descontextualizado, es decir, unidades líticas de la época inca sueltas y desperdigadas dentro del predio, que no estaban en sus ubicaciones primigenias y que con el tiempo fueron reutilizadas incluso sufriendo modificaciones.

El material histórico local, como unidad lítica, no recibió tratamientos sino de limpieza y desalinización.

Como elemento arquitectónico, los muros base de la crujía oeste del edificio de origen colonial, fueron consolidados mediante la recomposición de los tramos que habían sufrido desplazamientos, restituyendo algunas piezas líticas y también reintegrando los tramos que habían sido retirados para los vanos de acceso de las habitaciones republicanas.

Restitución y reintegración que se hizo con material histórico suelto del sitio y con piezas líticas nuevas.
No todas las piezas líticas nuevas tienen la muesca distintiva.

De la lectura se observa que los vestigios originales de muros incas, han recibido tratamiento de cabeceras para su preservación y conservación. Los muros recreados tienen núcleos de arena y grava sin tratamiento de cabeceras.

El material suelto descontextualizado, que se encontraba desperdigado por todo el Cusicancha, fue rejuntado y reutilizado como ya se dijo, para restituir las piezas líticas faltantes o quebrantadas de los muros inca originales, también para configurar los ambientes de las kanchas mediante el recrecimiento de muros sobre cimientos originales y en las proyecciones contemporáneas de estos mismos muros, para terminar de esbozar el trazado de las kanchas.

La existencia de las piezas sueltas en grandes cantidades, producto del desmontaje de las habitaciones inca, se había registrado muy temprano pues existe una tasación del año de 1785, mostrando las características del inmueble que se hallaba en el actual Cusicancha. Consistía en dos casas, una grande y otra chiquita, de dos patios y dos pisos, de adobe, con piedra de rostro de ala de mosca de la gentilidad en sus cimientos, escaleras y paredes. Existía una portada de piedras de la gentilidad y 8,000 piedras de rostro de ala de mosca de la gentilidad en cimientos, escaleras y paredes de la casa grande y 4 millares de piedras de rostro en los cimientos de la casa chica (INC, 2002).

Tal cantidad de piedra suelta inca no se elimina fácilmente, Mónica Paredes realizó un registro catastral en 1997, encontrando todavía en este sitio una alta concentración de piedra suelta.

Las alternativas eran dejarlas apiladas en un lugar o reutilizarlas en la restauración y puesta en valor.

Las estructuras in situ de material histórico local, han recibido diferentes formas de intervención entre liberación, conservación, consolidación vía recomposición y restitución.

Lo que no se hizo fue una selección meticulosa, rigurosa y diferenciada del material lítico utilizado. 

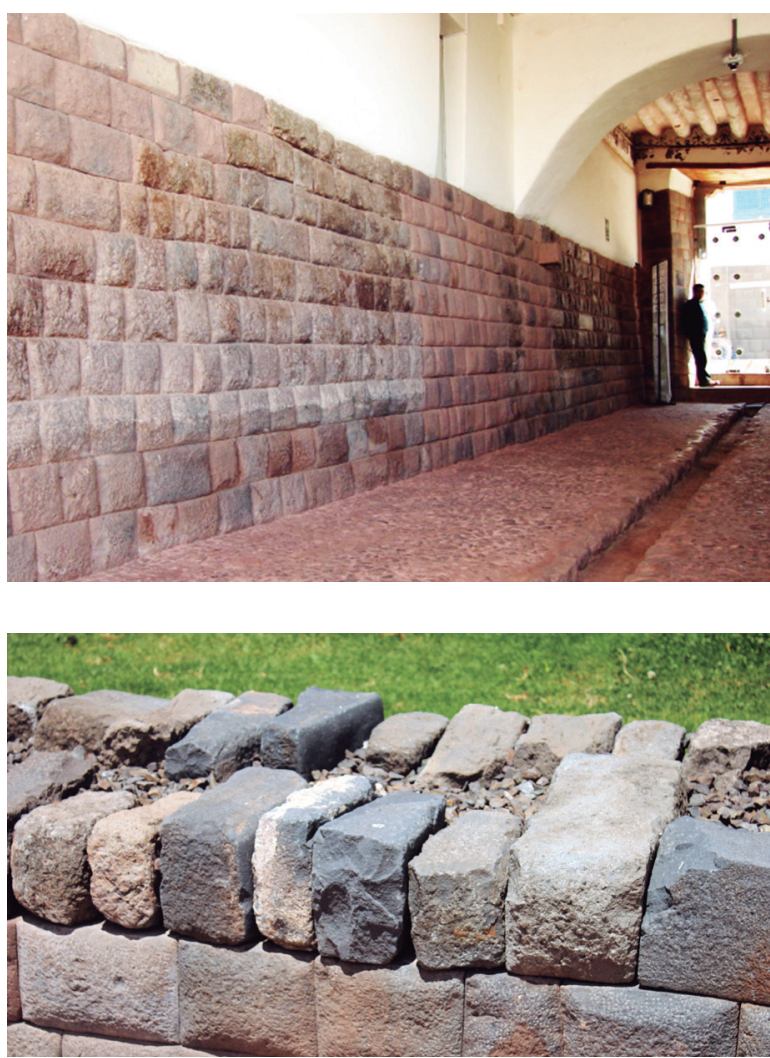

Hipótesis 2. El material tradicional utilizado en la conservación y restauración del Cusicancha favoreció a la recuperación de los materiales y tecnologías tradicionales del patrimonio arqueológico.

Material tradicional se refiere al material lítico recién canteado con las técnicas artesanales del Cusco y labrado en obra, que ha sido utilizado en la intervención.

La tecnología lítica tradicional ha servido a la conservación y restauración del patrimonio arqueológico, sin que sea la continuidad de la tecnología lítica inca, puesto que actualmente la técnica cuenta con herramientas que no están muy bien documentadas para la época inca.

Garcilaso de la Vega decía que "no tenían otras herramientas para trabajar que unas piedras negras llamadas "hihuana" (sic por Hihuaya), con la cual tallaban la piedra golpeándola y no cortándola” (1609/1976, Vol. I, Libro 2, p. 126, citado en Protzen, 2005, p. 215).

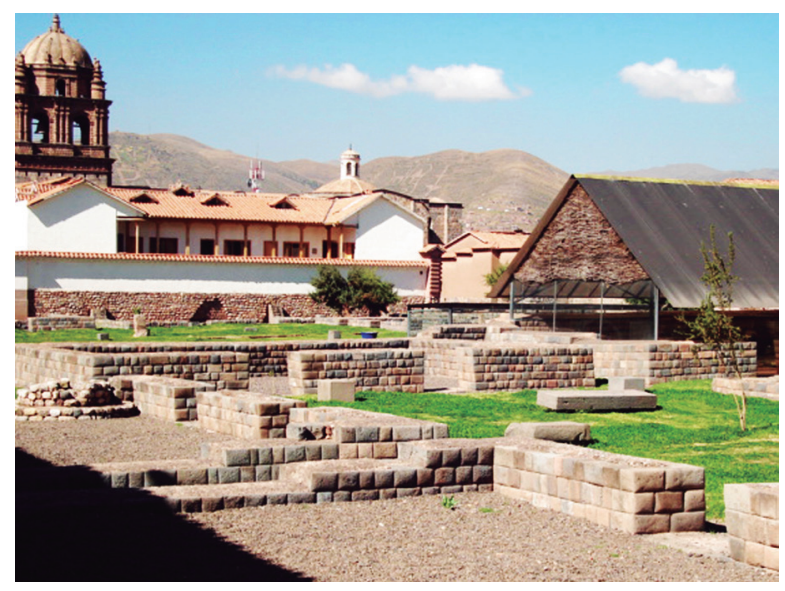

De izquierda a derecha y de arriba a abajo:

Figura 10

Muro inca consolidado, restituyendo tramos.

Figura 11

Muros recreados con núcleos de arena y grava sin mortero.

Figura 12

Recrecimiento de muros.

Sarmiento de Gamboa, otro cronista del siglo XVI, señalaba que:

Pachacuti Inga Yupangui reedifica la cidad del Cuzco. [...] trazó el pueblo por mejor orden que solía tener, y hizo las calles principales que tenía cuando los españoles entraron en el Cuzco, y repartió los solares para casas de comunidad y públicas y particulares, haciéndolas edificar de cantería muy polida. Y esto tanto, que a los que la hemos visto y sabemos que no tienen instrumentos de hierro ni acero para las labrar, nos pone admiración ver la igualdad y primor della y las junturas y betumen con que lo ligan... (1943:92).

Protzen, haciendo lo que hoy se conoce como arqueología experimental, realizó algunos ensayos para trabajar la piedra con las formas y acabados incas, lo que encontró fue que al usar el mismo tipo de piedra como percutor de la piedra tallada, el percutor que no tiene líneas de clivaje no deja huellas en la piedra tallada, por lo cual se puede suponer que no tuvieron herramientas de metal como lo dicen las crónicas del siglo XVI, si bien se encontraron algunos cinceles de 


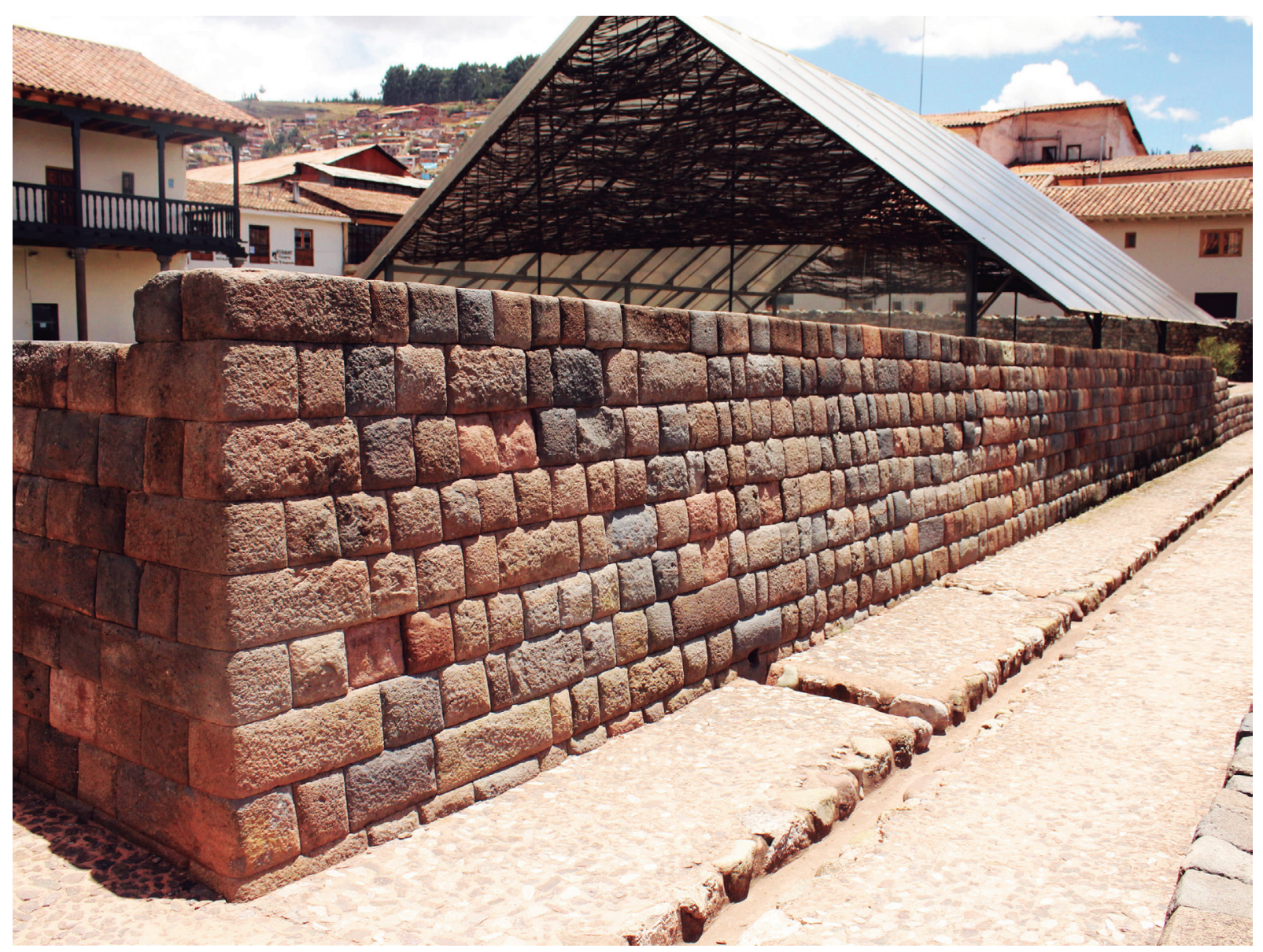

Figura 13

Muro inca restaurado, restituyendo piezas con material histórico local y material tradicional.

Llaqsa, una aleación de cobre, en Rumiqolqa, Raqchi y en Ollantaytambo; y el geólogo Robert Gordon de la Universidad de Yale, analizó objetos de cobre y bronce diseñados como cinceles que se encontraron en Machu picchu, por la poca cantidad de los hallazgos no se puede certificar su uso efectivo en los logros de la cantería y arquitectura inca.

La tradición lítica cusqueña se remonta al pasado, tiene componentes culturales de la tecnología lítica histórica y contemporánea, no es estrictamente prehispánica.

De las herramientas utilizadas destacan el cincel, el combo, el punto y la bujarda, que son propias de la tecnología importada de la península, actualmente también se usa la cortadora mecánica.
Junto con las herramientas, las técnicas de la cantería del Cusco son artesanales, aunque se han introducido técnicas de explotación masiva, se prefiere la explotación artesanal, igualmente para el tallado se prefiere el trabajo manual. Señalan los picapedreros que trabajan con el patrimonio, que tienen que ejecutar la piedra haciendo "jugar" la mano para lograr mejores resultados en el encastre de las piedras.

El Cusicancha es un sitio donde se ha utilizado la piedra para la puesta en valor de restos arqueológicos prehispánicos, con la finalidad de recuperar el concepto de kancha inca, a decir de los picapedreros que trabajaron en el sitio, el $70 \%$ de la piedra que se ha utilizado corresponde a la labra en obra.

Para la restauración del Cusicancha en Maruri, hemos traído de diferentes canteras, de Turricunca, de Huaqo- 
to, de Qochahuasi, de Cruz Pata, de Maras, de Amantoy, de seis canteras hemos traído (Saturnino Huillca, 55 años).

Los canteros actuales señalan enfáticamente que no pueden alcanzar la perfección de la tecnología lítica inca, sobre todo en los ensambles piedra con piedra.

Nosotros, la gente segunda mano de los incas, no sabemos cómo lograron tal calidad en el trabajo (Pedro Baca, 69 años).

La investigación realizada nos ha permitido identificar al Distrito de San Jerónimo de la Provincia del Cusco, como el centro de mayor concentración de Canteros y Picapedreros, de donde salen para trabajar tanto en la restauración del patrimonio como en obras civiles y en la construcción de nuevos edificios.

El distrito de San Jerónimo, provincia del $\mathrm{Cusco}^{1}$ en la época inca, fue cuna de ayllus reales, actualmente su población habla los idiomas quechua $\mathrm{y}$ español, y mantiene relaciones de solidaridad como el ayni, la minka y la jurka.

Las entrevistas individuales y el focus group se realizaron con canteros y picapedreros, cuyo grado de instrucción del $80 \%$ del grupo es educación primaria incompleta, el otro $20 \%$ ha estudiado secundaria, uno de ellos es egresado de Escuela Taller y otro tiene estudios en la Escuela de Bellas Artes "Diego Quispe Tito".

La percepción de los canteros actuales sobre la tecnología lítica de los incas ha quedado en el conocimiento popular, en el supuesto de la existencia de un líquido que servía para hacer tajos en la piedra, o la existencia de una yerba que el ave Jaqachu utilizaba para tallar piedras, destacan insistentemente que no conocen las técnicas, conocen el material y algunas herramientas tanto de metal como de piedra, pero la técnica espe-

1. Ubicado a $11 \mathrm{~km}$ de la ciudad del Cusco, perteneció al antiguo reino de los Omas, habitado por los antis en la parte alta cerca de Huaqoto, y los maras. Los cronistas mencionan la presencia del pueblo de Oma a dos leguas del Cusco, relacionado con el Huarachico. Existían 14 ayllus, varios de los cuales eran ayllus reales ubicados dentro de un patrón de ocupación disperso cuyo centro era el Cusco. En la época colonial estos ayllus fueron reducidos a poblaciones de acuerdo con las ordenanzas de Felipe II, y en 1571 se funda la Parroquia de San Jerónimo, para adoctrinar y concentrar a la población. Según el censo del 2007 tiene 33,884 habitantes. cialmente de armado de muro fino y junturas, señalan desconocer, pero admirar profundamente.

Hipótesis 3. El material tradicional utilizado en la conservación y restauración del Cusicancha sirvió a la restitución de elementos y tramos dentro del proceso de restauración del patrimonio arqueológico, para visualizar un segmento del trazo de la ciudad inca.

El material tradicional se encuentra por todo el conjunto en los tramos de muro inca restituidos para la configuración de las kanchas.

Se distingue por una muesca circular pequeña hecha en cada elemento lítico que es ensamblado para el recrecimiento de muros, sin embargo, no todas las piezas nuevas tienen esta distinción, otras son notorias por el acabado de su superficie logrado mediante abujardado tosco, prestándose a confusión, por lo que el ojo observador debe ser experto para hacer las diferencias.

Material tradicional también se ha requerido para la reintegración de los muros por todo el conjunto y la reintegración de elementos como en las puertas de doble jamba que se encuentran en los muros prehispánicos que hacen de bases en las crujías de adobe, donde no es propiamente restitución porque se trata de completamientos de piezas faltantes, igual que en los vanos que resultaron evidentes con la excavación arqueológica que se realizó en la vereda de Maruri.

La reconstrucción de los vanos de doble jamba en el muro también reconstruido de la calle Romeritos se hizo con material tradicional, esta intervención ha sido la más rebatida por algunos de nuestros entrevistados, catalogada como una falsificación aunque tiene piezas identificadas como contemporáneas y se encuentra documentada en los informes de restauración.

Algunos entrevistados, como el arquitecto Roberto Samanez Argumedo, cuestionan específicamente esta intervención señalando que es una reconstrucción innecesaria, sin embargo, la mayoría lo acepta anotando que se sustenta en evidencia arqueológica porque existen los arranques de estas entradas y otros entrevistados como la arqueóloga Carmen Farfán y el arqueólogo Julio Maza, con relación al uso 


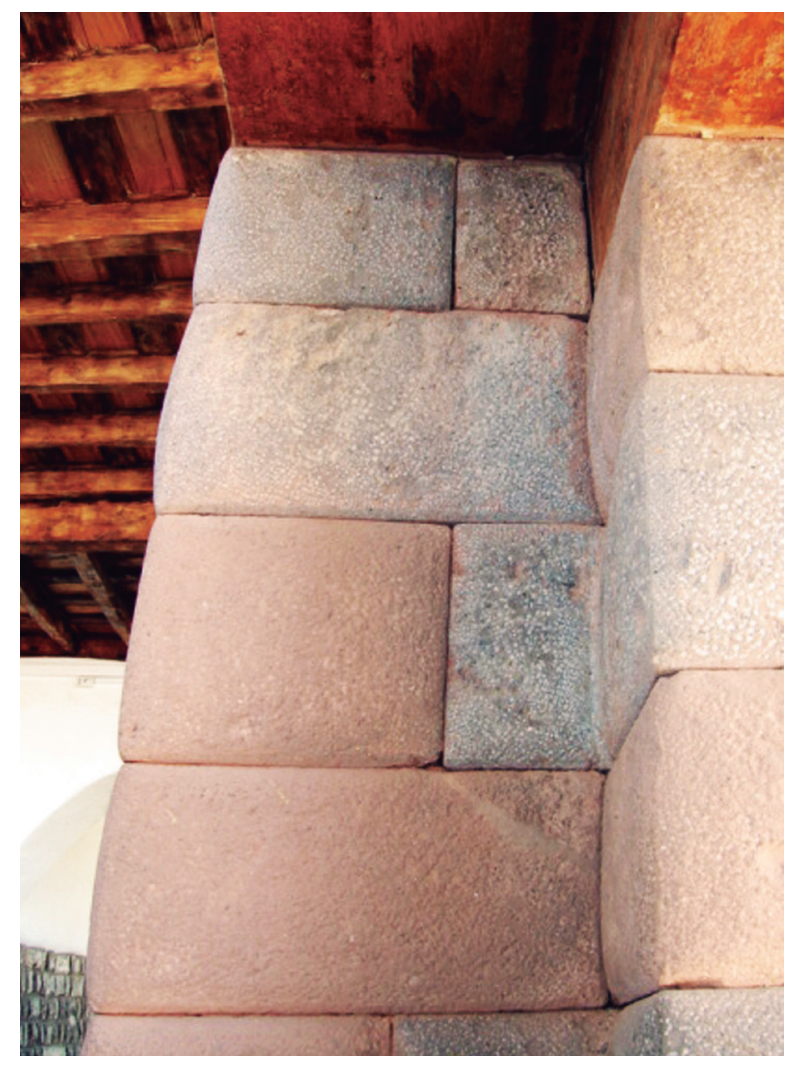

de materiales, se inclinan a favor del uso de material tradicional para la elevación del muro perimetral, porque no agrede a la autenticidad del patrimonio inca, en lugar de otros materiales como rejas, vidrio o concreto.

La mampostería rústica del muro de la calle Romeritos fue producida íntegramente por los talladores de piedra tradicionales, esta restauración de fantasía, es de caliza con unidades esferoides de $0.20 \mathrm{~m}$ de diámetro y sirve como muro perimétrico.

Algunos elementos como los vanos de doble jamba y los muros fueron recreados con material tradicional en un acomodo sin mucha selección, existiendo espacio para el orden y también para el caos, en hiladas puestas sin mortero y poniendo las piezas, entre nuevas y descontextualizadas, solo por lograr trazos.

Hipótesis 4. El material moderno utilizado en la conservación y restauración del Cusicancha favoreció a la protección de los hallazgos arqueológicos de los factores de deterioro ambiental y social.

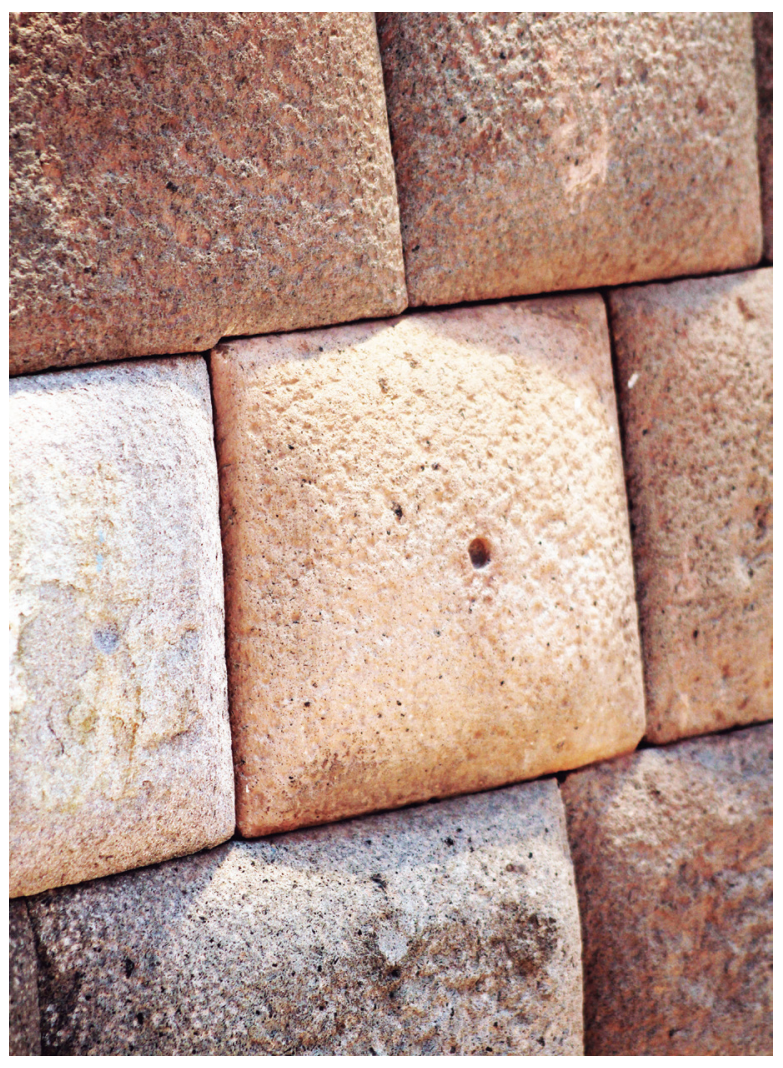

Material moderno se refiere al material contemporáneo, extraño al material esencial del patrimonio arqueológico, que se ha utilizado para la preservación y conservación de elementos.

En el Cusicancha los hallazgos arqueológicos especiales, como son contextos de entierros, contextos de ocupación inca con vestigios de incendio y colapso de techos, fueron cubiertos con estructuras de metal y policarbonato, en uno de los casos, copiando la inclinación del hastial y aleros de techo inca.

Estos hallazgos permanecen in situ, conforme a las recomendaciones de las Cartas internacionales.

En otro uso, se tiene vidrio templado para cubrir los vanos de doble jamba y calles transversales inca en la calle Romeritos, así como en el vano de la calle longitudinal, que es actualmente la puerta de acceso al conjunto del Cusicancha por la calle Maruri, y en el otro vano de acceso en la Plazoleta de Santo Domingo.

También existe vidrio templado para el cerramiento de Maruri, hacia la esquina con Romeritos, que 

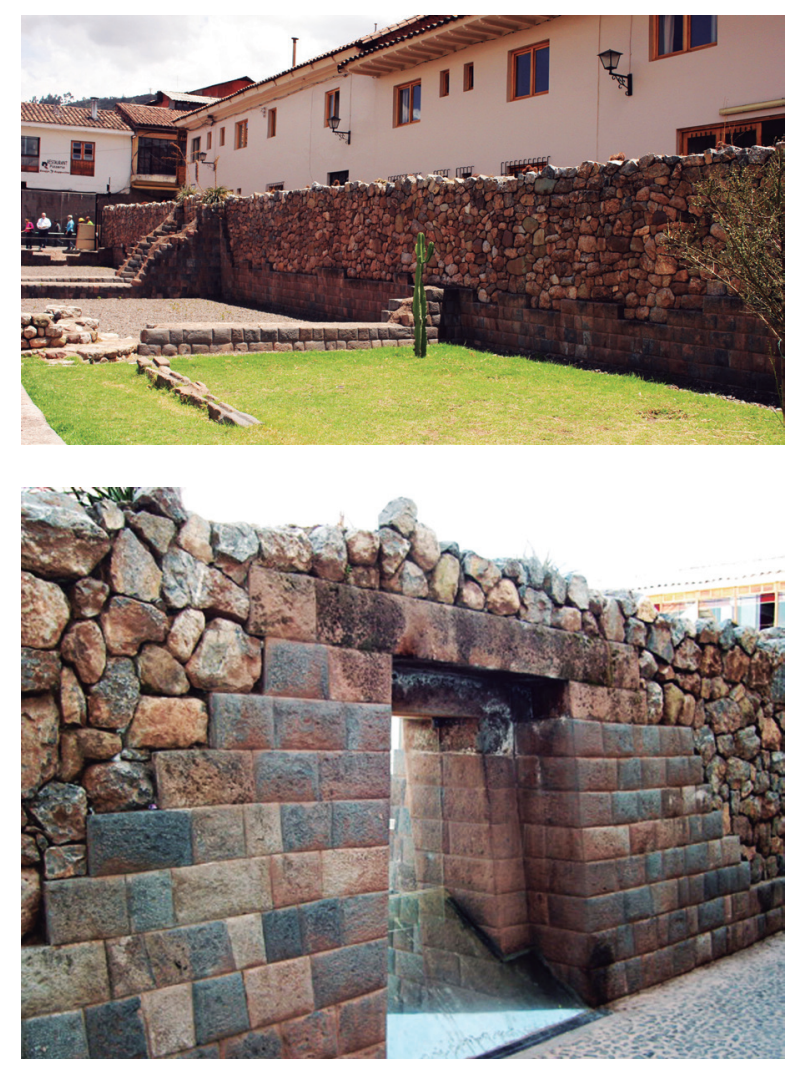

no remata la altura de dos pisos que corresponde al tejido urbano, pero resguarda al predio dándole además transparencia, para que el transeúnte pueda ver el conjunto desde la calle.

Esta abertura rompe sorpresivamente con la armonía volumétrica de la Manzana 37, pero permite la visual de un tipo de patrimonio que es apreciado en el Cusco.

Hipótesis general. A mayor uso de material histórico local y material tradicional, mayor preservación de la autenticidad de los materiales del Cusicancha.

La intervención en los vestigios auténticos del Cusicancha ha considerado los tipos de tratamiento admitidos por los documentos internacionales: conservación, anastilosis (recomposición) y consolidación.

Sin embargo, también ha postulado por una presentación interpretativa pedagógica del patrimonio, ha optado por mostrar un tramo de la traza urbana inca, sus calles, kanchas, canales para colectar aguas, etc., recurriendo a la restitución de unidades líticas de los
De izquierda a derecha y de arriba a abajo:

Figura 14 (página anterior)

Líticos de andesita rosada producidas con técnicas tradicionales.

Figura 15 (página anterior)

Muesca en material tradicional.

Figura 16

Reconstrucción de muro Romeritos con unidades líticas nuevas.

Figura 17

Reconstrucción de jamba con material tradicional.

muros, al recrecimiento de muros y a completamientos o reintegraciones del trazo de las kanchas.

La Carta Internacional para la Gestión del Patrimonio Arqueológico (1990), habla de "reintegración" con propósitos pedagógicos e interpretativos para evitar el congelamiento del sitio arqueológico.

El arquitecto Américo Carrillo Rosell, director de la restauración del Cusicancha y funcionario del Ministerio de Cultura, indicó que una reconstrucción se distingue de la restitución por el uso mayoritario de materiales nuevos, la restitución, señaló, comprende una menor cantidad de material nuevo frente a la existencia de evidencia auténtica en mayor porcentaje y que el rescate del concepto de kancha y de la traza urbana inca del Cusco, es lo que ha primado en su intervención.

Un aspecto a considerar es el impacto que ha tenido la intervención del Cusicancha en la opinión pública local; hecha la revisión periodística del momento contemporáneo a la entrega de la obra encontramos 


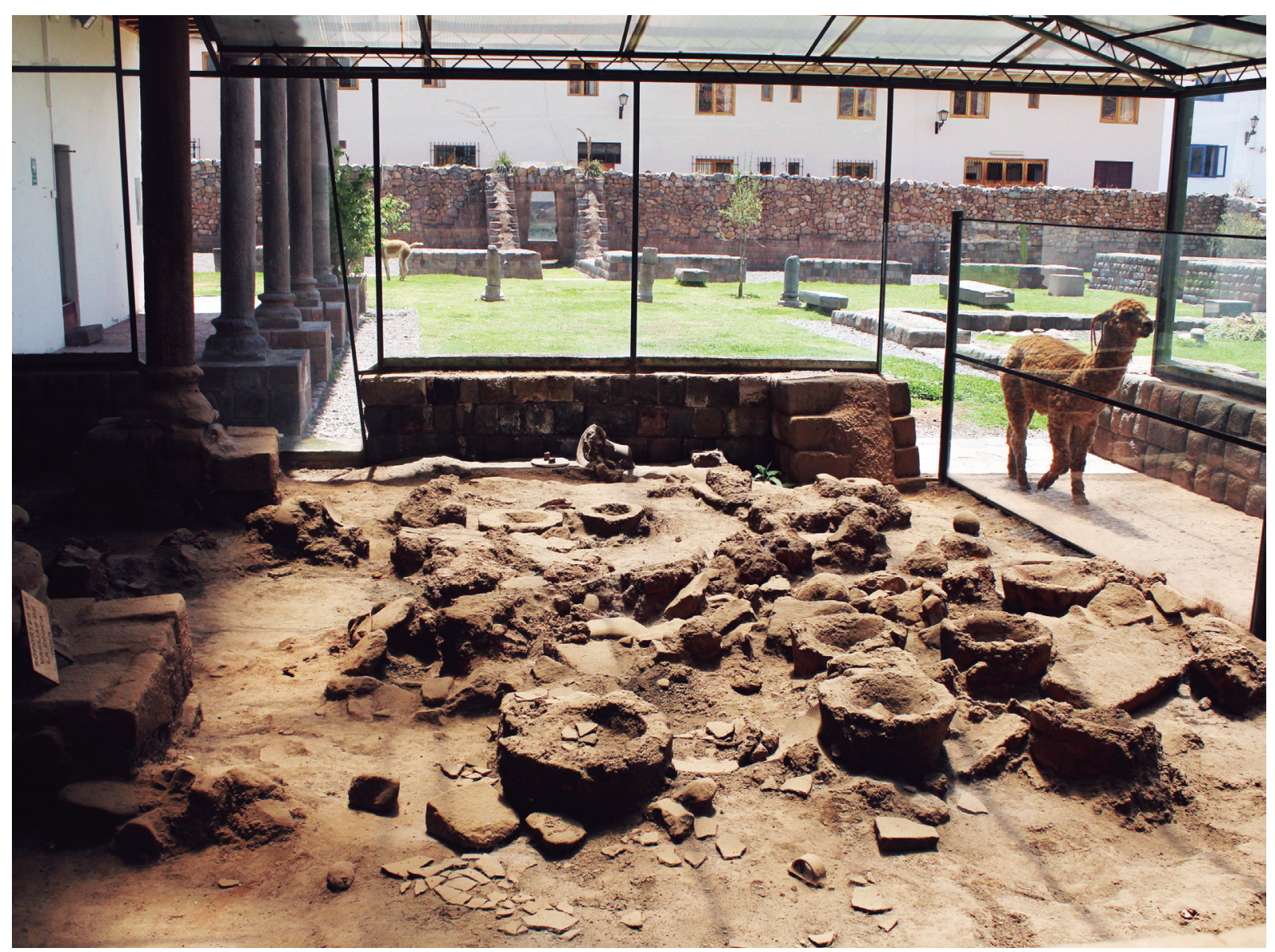

mucho entusiasmo por el resultado, incluso las autoridades anunciaban el propósito de seguir el tipo de intervención en otros predios de la Manzana 37, frente a la crítica de algunos medios en el sentido de que no se debía crear un Cusco inca de fantasía, haciendo "aparecer" un Cusicancha donde no se debía negar la pátina del tiempo, que en este caso son las casas que existen sobre los restos de arquitectura inca.

Las entrevistas realizadas para el presente estudio a arqueólogos y arquitectos, han arrojado una opinión favorable por la recuperación de un tramo de la traza urbana inca, y por el tipo de intervención y materiales utilizados:

Se ha partido por la consolidación de los elementos hallados y después se han reintegrado algunos elementos compositivos para poder dar la definición de la morfología encontrada, se han añadido algunas hiladas con elementos diseminados, en algunos casos muy pocos con elementos nuevos, es decir, traer material de cante- ría de otros espacios para, más que nada, definir ciertas morfologías, por eso es que los muros al interior no exceden del metro de altura, a excepción de la parte perimetral que está un poco alta y otros porque así se los ha encontrado, y también existe una lectura de muro inca diferente a un muro contemporáneo que es burdo, que vienen a ser añadiduras que se han dado en el tiempo, claro, por la misma situación de uso que se le daba al edificio, pero eso se ha pretendido y se ha cuidado bastante de utilizar elementos propios (entrevista a la arqueóloga Carmen Farfán, 20 de octubre de 2010).

En cuanto a los usos de los materiales de la época inca y época colonial todo está definido, entonces creo que todo lo que se ha hecho es bueno, no podemos decir que ha sido regular, hay algunas partes donde se ha sobredimensionado el muro, eso obedece a los fines de seguridad, es muy funcional ese muro, porque peor sería pues poner otros elementos como vidrios, palancas, etc., además, se estaría rompiendo la estética de una kancha inca, un muro de piedra bienvenido sea (entrevista al arqueólogo Julio Maza, 18 de octubre de 2010). 


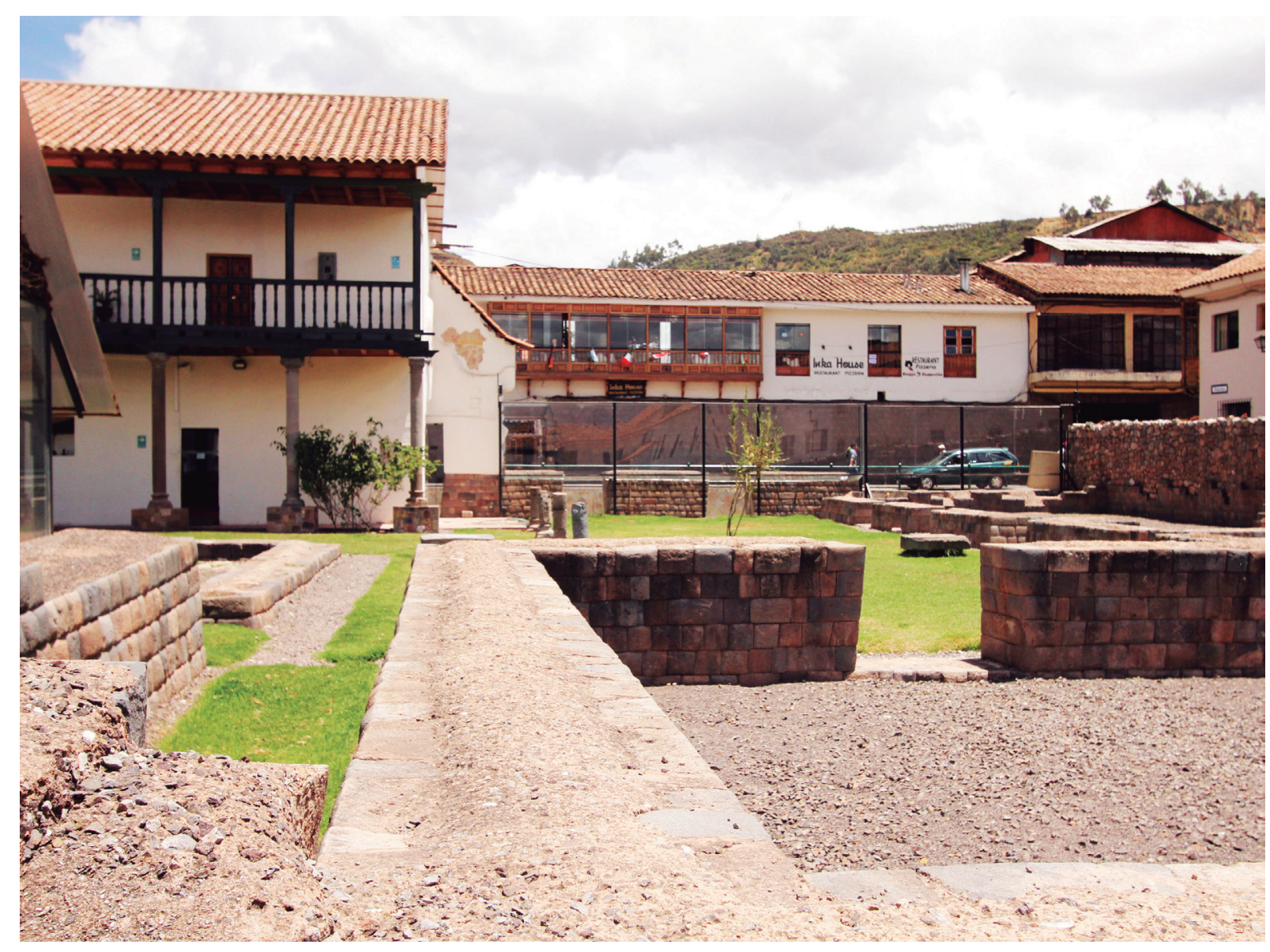

Los entrevistados consideran que los materiales líticos empleados para la intervención del Cusicancha, favorecieron a la preservación de la autenticidad de los materiales del patrimonio inca.

La Carta de Burra, en su art. 24, dice que "las asociaciones significativas entre la gente y un sitio deben ser respetadas, preservadas y no oscurecidas. Se deberán investigar e implementar las oportunidades de interpretación, conmemoración y celebración de estas asociaciones".

Indagando un poco más sobre la percepción que el poblador local tiene acerca del patrimonio arqueológico:

Para la población creo que pesa más lo prehispánico, además que por ley lo prehispánico automáticamente está declarado, la gente lo sabe. Están más identificados con los restos incas, pero al mismo tiempo les significa problemas, ese es el conflicto,...la población aprecia todo lo que tiene valor patrimonial, inclu-
Figura 18 (página anterior)

Vidrio y policarbonato protegiendo hallazgos arqueológicos.

Figura 19

Vidrio templado en cerramiento de la esquina de Maruri. 


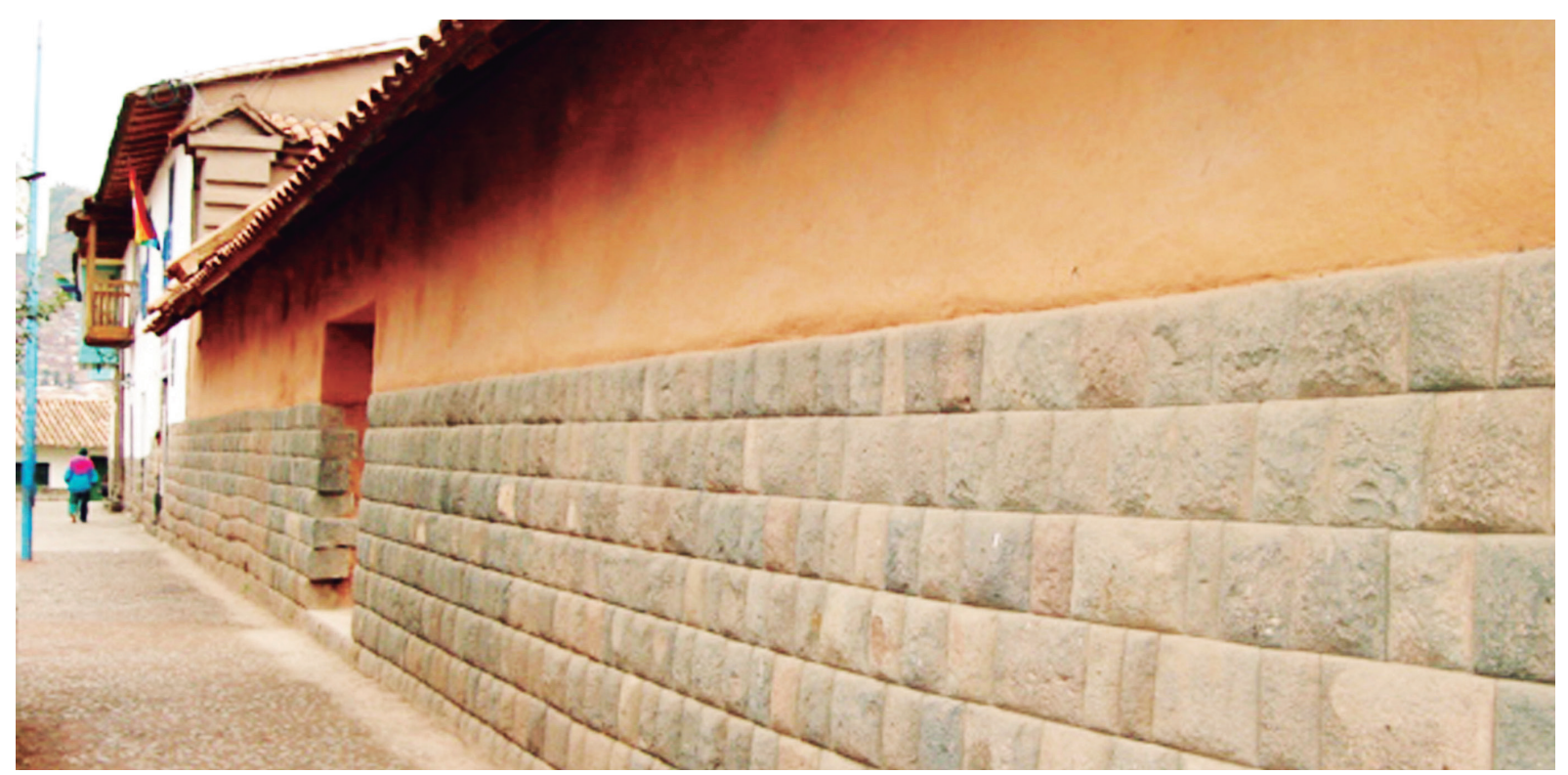

yendo también lo colonial, ahora la gente está viendo con otros ojos sus casonas coloniales que tienen otro precio, también lo están viendo así, pero se identifican creo que más con los restos prehispánicos (entrevista a la arqueóloga Mónica Paredes: 26 de octubre de 2010).

Sin embargo, aunque el recrecimiento de muros en el Cusicancha es reversible, puesto que están armados en seco y no tienen mortero de amarre, en lo que corresponde a recreaciones, vale decir reintegraciones y reconstrucciones, dejar los tramos auténticos visibles sobre o debajo de la cota, para mostrar cuál ha sido la evidencia arqueológica sobre la que se ha proyectado, comunicaba mejor la significación del sitio.

No hay líneas de división ni retiros para una lectura más compresiva y firme de la intervención, no ha habido un uso selectivo metódico en estricto de los materiales líticos, el material histórico local y el material tradicional, se han usado indistintamente.

La intervención ha terminado ocultando la huella arqueológica, salvo en algunos tramos de los restos incas y en los restos de estructuras preinca.

\section{Conclusiones}

1. Se ha verificado que en el Cusicancha, el material histórico local ha sido conservado in situ y, en consecuencia, preserva la autenticidad del patrimonio arqueológico de la época inca en su condición de parte componente de un tramo de la traza urbana inca. El material suelto de la época inca que se ha encontrado descontextualizado también interviene en la preservación de la autenticidad del patrimonio local, ha sido reutilizado para la reintegración de elementos de muro inca original, para el recrecimiento de muro sobre evidencia de cimentación inca, en proyecciones de trazo de las kanchas inca para rematar su morfología, sin embargo, su uso no ha sido sistematizado.

2. El material tradicional coadyuva en la preservación de la autenticidad del material esencial del patrimonio inca cusqueño, en la medida que se puede leer como material nuevo. Se ha verificado que no existe registro ni marcado sistemático de este material y en esta medida, atenta contra la autenticidad de los materiales del Cusicancha.

3. Se confirma la hipótesis específica de que el material tradicional favoreció a la recuperación y continuidad del uso de materiales y tecnologías tradicionales y a la preservación de la autenticidad de los materiales del patrimonio arqueológico del Cusicancha cuando se distingue como material nuevo y aunque no significa la continuidad de la tecnología lítica inca, se utilizó para la restitución, reintegración y reconstrucción de elementos y tramos de la traza urbana inca, con fines pedagógicos, sin colisionar con la tipología del sitio arqueológico. 


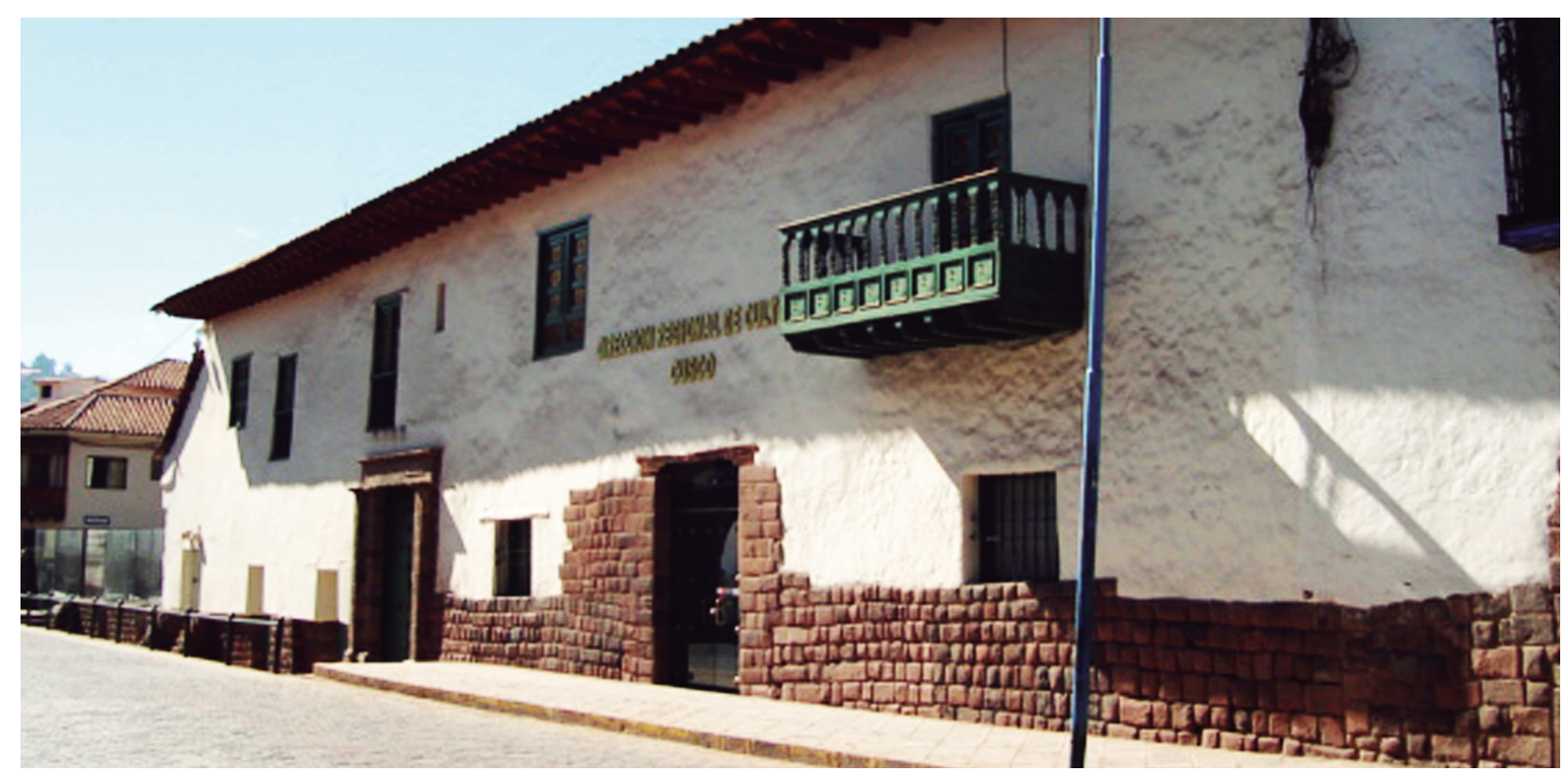

4. El material tradicional de piedra canteada, labrada en obra, se distingue por una muesca y también por el acabado abujardado de su superficie, y sirvió para la restitución de unidades líticas en muro inca original, el recrecimiento de muro sobre cimentación inca, la proyección para rematar morfologías, para la reconstrucción de elementos arquitectónicos, como jambas de estilo inca, y para la restauración de fantasía en muro perimétrico.

La hipótesis afirmaba que el material tradicional utilizado en la conservación y restauración del Cusicancha sirvió a la restitución de elementos y tramos para visualizar un segmento del trazo de la ciudad inca, sin embargo, después del desarrollo de la investigación se ha verificado que se trata de una reintegración parcial y reconstrucción, debido a que la cantidad de evidencia física arqueológica es menor en proporción a los segmentos recreados vía recrecimiento de muros y reconstrucción de elementos.

5. Se confirmó la hipótesis de que el material moderno: fierro y vidrio, fue requerido para proteger hallazgos especiales de escenas arqueológicas, que como componentes del significado del patrimonio quedaron in situ y para cerrar vanos hacia la calle, armonizando con la tipología del sitio arqueológico.
Figura 20 (página anterior) El Cusicancha restaurado hacia Intipampa (Santo Domingo).

Figura 21

Fachada de Maruri. 


\section{Bibliografía}

Agurto Calvo, S. (1987). Estudios acerca de la construcción Arquitectura y Planeamiento Incas. Lima: Cámara Peruana de la Construcción CAPECO.

Aparicio Estrada, N. y Fernández Díaz, P. J. (1986). Proyecto para el Centro Cultural del Cusco. Tesis para optar al Título de Arquitecto en la Facultad de Arquitectura, Urbanismo y Artes Plásticas de la UNSAAC, Cusco, Perú.

Bermudez Zamalloa, B. (1984). Evidentes Calles Inka en el Cusco Contemporáneo. Informe inédito de Práctica Pre Profesional. Carrera Profesional de Arqueología, UNSAAC, Cusco, Perú.

Feilden, B. M. y Jokiletho, J. (1995). Manual para el manejo de los Sitios Culturales del Patrimonio Mundial. Bogotá: Colcultura.

Hayakawa Casas, J. (2002). Restauración Monumental en Lima en el Periodo 1920-1990. Tecnia, 12, 1. Lima: Universidad Nacional de Ingeniería.

Hernández Mora, I. (2006). Patrimonio y Arqueología Histórica. Reflexiones desde una epistemología antropológica. Recuperado desde http://www.ohch. cu/boletín-arqueológico Boletín del gabinete de arqueología, La Habana.

ICOMOS (1990). Carta Internacional para la gestión del patrimonio arqueológico, preparada por el Comité Internacional para la Gestión del Patrimonio Arqueológico (ICAHM) y adoptada por la Asamblea General del ICOMOS en Lausana. Recuperado desde http://www.international.icomos.org/charters/ arch_sp.htm

ICOMOS (1999). Carta de Burra, Carta del ICOMOS Australia para Sitios de Significación Cultural (Art. 25, $4.2,10)$.

ICOMOS. (2003). Principios para el análisis, conservación y restauración de las estructuras del Patrimonio Arqui- tectónico. Recuperado desde http://www.international.icomos.org.

INC (2002). Informe de Evaluación e Investigación Arqueológica Kusicancha. Dirección de Investigación y Catastro, Cusco.

INC (2004a). Kusikancha, Proyecto 2004. Arquitectura. Cusco: Dirección de Conservación del Patrimonio Inmueble - Sub Dirección de Obras.

INC (2004b). Restauración y Puesta en Valor Kusikancha Ex cuartel 27 de noviembre. Cusco: Dirección de Conservación del Patrimonio Inmueble - Sub Dirección de Obras. Informe Final Arqueológico.

INC (2004c). Informe Anual 2004 Restauración y Adecuación del local "Kusicancha". Cusco: Dirección de Conservación del Patrimonio Cultural Inmueble.

Protzen, J. P. (2005). Arquitectura y Construcción Incas en Ollantaytambo. (Primera edición en castellano). Lima: Fondo Editorial Pontificia Universidad Católica del Perú.

Rivera Blanco, J. y Pérez Arroyo, S. (2000). Carta de Cracovia, principios para la conservación y restauración del patrimonio construido, Versión española del Instituto Español de Arquitectura, Universidad de Valladolid.

Schávelzon, D. (1987). Cambio y Transformación, la restauración arqueológica en América Latina entre 1970 y 1980. Anales del Instituto de Arte Americano e Investigaciones Estéticas "Mario Buschiazzo", 25, 69-82. Universidad de Buenos Aires.

Samanez Argumedo, R. (1986). La Conservación del patrimonio monumental a través de la historia. Revista del Museo e Instituto de Arqueología, 23. UNSAAC, Cusco. 